\title{
Confiança nas instituições políticas: diferenças e interdependência nas opiniões de jovens e população brasileira
}

\author{
Guilherme A. Russo ${ }^{1}$ \\ Roberta Gurgel Azzi² \\ Charlene Faveri ${ }^{3}$
}

\begin{abstract}
Este artigo contribui para o estudo sobre confiança nas instituições no Brasil ao analisar os dados do Barômetro das Américas de 2014 e 2017 e de uma pesquisa original com 487 jovens em 2016. Os objetivos são: 1) identificar variações nos níveis de confiança em diferentes instituições e entre a população em geral e os jovens; 2) mapear como as opiniões sobre as diferentes instituições se relacionam entre si; e 3) analisar a relação entre experiências de participação política, consumo de mídia e confiança nas instituições. Os resultados apontam que as instituições políticas como partidos e eleições são vistas de forma negativa, principalmente quando comparadas às Forças Armadas. Análises fatoriais apontam que as opiniões sobre instituições se distribuem em duas dimensões - uma que captura a propensão a ter mais confiança nas instituições e outra que discrimina opiniões favoráveis às instituições militares. Finalmente, análises de regressão indicam que indivíduos que participaram de reuniões políticas e usaram menos a internet têm um nível de confiança mais alto nas instituições.
\end{abstract}

Palavras-chave: confiança nas instituições; opinião pública; teoria social cognitiva; jovens

\section{Introdução}

Instituições têm papel integrador na sociedade, pois viabilizam a convivência coletiva (North, 1991). São elas que formalizam as regras, os procedimentos e as condutas entre indivíduos, e buscam, num regime democrático, favorecer a convivência harmoniosa e pacífica ao manter a igualdade política entre os cidadãos (Dahl, 1989). No processo de formação dessas regras, os cidadãos delegam às instituições e seus representantes o poder de decisão pressupondo seu fundamento alicerçado na moral, ou seja, é esperado que as instituições atuem segundo os termos e objetivos para os quais foram criadas (Miller e

\footnotetext{
${ }^{1}$ Centro de Política e Economia do Setor Público (Cepesp), Fundação Getúlio Vargas (FGV), São Paulo (SP), Brasil. E-mail: <guilherme.russo@fgv.br>. Orcid: <http://orcid.org/0000-0001-8763-5698>.

2 TSC - Centro de Estudos e Pesquisas, Bragança Paulista (SP), Brasil.

E-mail: <azzi.tsc@gmail.com>. Orcid: <http://orcid.org/0000-0003-0971-7852>.

3 TSC - Centro de Estudos e Pesquisas, Bragança Paulista (SP), Brasil.

E-mail: <chafaveri@hotmail.com>. Orcid: <http://orcid.org/0000-0003-4020-780X>.
} 
Listhaug, 1999). Entretanto, nem sempre a percepção do funcionamento de instituições se equipara às expectativas que os cidadãos têm a respeito delas, o que pode levar um regime democrático a altos níveis de descontentamento com as instituições políticas e até a questionamentos sobre a democracia como regime (Easton, 1975).

Segundo estudos de cultura política, altos níveis de insatisfação com as instituições democráticas podem se tornar um problema para a estabilidade política, pois um grau mínimo de confiança nas instituições do sistema democrático e apoio a elas é visto como crucial para a legitimidade e o funcionamento do sistema político, principalmente em novas democracias como a brasileira (Mishler e Rose, 1997; Booth e Seligson, 2009). Portanto, é importante entender não só quais instituições recebem menor confiança da população brasileira, mas também como esses indivíduos formam opiniões sobre essas instituições (Moisés, 2005a). Além do mais, estudos recentes indicam que as novas gerações têm menor nível de confiança nos partidos políticos e adesão à democracia tanto em democracias antigas como naquelas mais jovens, o que sugere uma interpretação pessimista sobre a probabilidade de consolidação da democracia (Seligson, 2007; Corral, 2008; Foa e Mounk, 2016, 2017).

Este artigo contribui para o estudo sobre os níveis de confiança nas instituições políticas no Brasil de três formas. Primeiro, o artigo apresenta resultados de uma pesquisa original focada em entender as opiniões de jovens da região metropolitana de Campinas ${ }^{4}$, cujos dados foram coletados no primeiro semestre de 2016, e compara os níveis de confiança nas instituições encontrados na pesquisa com resultados da pesquisa Barômetro das Américas de 2014 e de 2017, composta por uma amostra representativa da população. Segundo, o artigo se utiliza das três pesquisas para mapear como os níveis de confiança em diferentes instituições se relacionam entre si e indica que a estrutura dos níveis de confiança da população em diferentes instituições políticas do país segue duas dimensões (fatores latentes): uma relacionada a preferências sobre democracia como regime e outra, menos importante, sobre as instituições dedicadas à manutenção da ordem (polícia e Forças Armadas). Terceiro, o artigo faz uso da teoria social cognitiva para discutir como as atitudes em relação às instituições são modeladas e, assim, explicar o porquê de certos fatores como experiências de participação, consumo de mídia, fatores demográficos e percepções de desempenho institucional serem correlatos dos níveis de confiança.

Os resultados das análises das três pesquisas corroboram os baixos níveis de confiança nas instituições políticas encontrados em pesquisas anteriores, mas também demonstram que há significativas diferenças entre esses níveis para as diferentes instituições, assim conduzindo a duas dimensões que dão estrutura às opiniões tanto dos

\footnotetext{
4 Agradecemos aos colegas do antigo Núcleo de Estudos Avançados em Psicologia Cognitiva e Comportamental (Neapsi), da Faculdade de Educação da Unicamp, que colaboraram no desenho da pesquisa e coleta de dados. Agradecemos também às escolas e aos pais que aceitaram a participação de seus alunos e filhos no estudo, e principalmente aos jovens. Durante a coleta de dados para este artigo, os autores Guilherme A. Russo e Roberta Gurgel Azzi eram filiados ao Departamento de Ciência Política da Vanderbilt University (EUA) e Faculdade de Educação da Universidade Estadual de Campinas (Unicamp), respectivamente.
} 
jovens como da população em geral. Mais além, os resultados indicam que há pequenas diferenças entre os níveis de confiança nas instituições da população em geral e dos jovens, principalmente quando comparamos os relacionados às instituições de ordem com os referentes àquelas da democracia representativa. Por fim, as regressões multivariadas indicam que o nível de confiança nas instituições está relacionado ao nível de engajamento dos indivíduos com a política, ao consumo de mídia e às percepções de desempenho da economia e do governo, tanto para os jovens como para a população em geral.

\section{Confiança nas instituições}

Como os indivíduos não possuem os recursos necessários para dominar todas as áreas da vida cotidiana, com frequência estes têm de delegar seu bem-estar, segurança e preferências a instituições e representantes que atuam nessas áreas - como políticos, médicos, policiais, líderes religiosos, entre outros (Bandura, 2008). Esse processo de delegação, no entanto, depende de um grau de confiança nos agentes responsáveis por exercer funções em nome daqueles que as delegam. Dada a importância dessa relação na organização da sociedade, estudos sobre desenvolvimento político dedicam atenção sobre como os cidadãos avaliam as instituições do regime político desde meados do século XX (Lipset, 1959; Huntington, 1968). O acúmulo de estudos dessa tradição aponta uma associação proeminente entre as preferências da população em relação à democracia e a estabilidade e qualidade de um regime democrático (Diamond, 1999). Alguns autores chegam até a defender que um regime democrático só é legítimo e estável se a população, de modo geral, confiar nas instituições e nas pessoas que as representam, pois a democracia seria então "the only game in town" (Linz e Stepan, 1996). Segundo essa lógica, se a população não confiar nos seus representantes políticos, nos processos eleitorais e até mesmo nas forças policiais, haverá uma tendência ao descumprimento de regras e diretrizes do Estado, favorecendo assim o declínio das instituições e da democracia (Silva e Caminha, 2012).

Por outro lado, a literatura de opinião pública aponta que a percepção da democracia e de suas instituições está fortemente ligada ao desempenho (performance) econômico e social do governo (Carlin, 2006; Ceobanu, Wood e Ribeiro, 2010; Colen, 2010; Lopes, 2004). Isto é, a confiança nas instituições sofre influências do contexto social, pois ambientes marcados pela inaptidão do governo em solucionar problemas sociais favorecem a impressão de que as instituições democráticas são pouco eficazes (Anderson, 1995; Weil, 1989). Evidências em favor desse argumento são países latino-americanos, onde frustrações com corrupção e deficiências das novas democracias em promover mudanças econômicas e sociais têm levado a baixos níveis de confianças nas instituições (Seligson, 2002). O Brasil não é exceção a esse padrão. Resultados do Latinobarômetro de 1996 e Barômetro das Américas nos últimos anos apontam que a população brasileira tem 
um dos níveis mais baixos de apoio às instituições políticas entre os países da América Latina (Lopes, 2004; Russo, 2016).

Entretanto, diferenças no campo de atuação e eficiência de diferentes corpos governamentais podem levar os indivíduos a confiar em certas instituições, mas não em outras. Por exemplo, estudos mostram que, enquanto há baixa confiança nas instituições político-representativas como Congresso, eleições e partidos políticos, as populações latino-americanas têm altos níveis de confiança nas Forças Armadas (Seligson e Carrión, 2002; Montalvo, 2009; Zechmeister, 2014)5. Ademais, um novo conjunto de estudos sugere que, apesar de haver razão para preocupação sobre baixos níveis de confiança nas instituições políticas, muitas vezes essa avaliação é superestimada, pois na verdade há um crescimento no número de indivíduos que não estão satisfeitos com o funcionamento da democracia, mas não deixaram de apoiá-la como melhor regime para seu país, nem de participar do processo eleitoral (Dalton, 1999; Norris, 1999). Segundo essa nova interpretação, o aumento nesse grupo de cidadãos críticos, às vezes chamados de democratas insatisfeitos, não seria necessariamente negativo para a estabilidade da democracia, pois se estes mantiverem seu apoio à democracia mesmo com certo grau de insatisfação com o desempenho atual das instituições, essas atitudes devem levar à cobrança de melhorias e não a alternativas ao regime democrático (Klingemann, 1999; Inglehart, 1999; Norris, 1999).

No entanto, essa visão mais otimista sobre níveis baixos de confiança nas instituições democráticas não vai contra o modelo proposto por Easton $(1965,1975)$ de que o baixo apoio específico a instituições específicas se torna um baixo apoio difuso ao sistema com o passar do tempo, como um reservatório que, quanto menor o nível de água, mais rápido é o declínio. Isto é, apesar de um apoio difuso alto em princípio, o baixo apoio específico às instituições afeta o apoio difuso à democracia como sistema ao longo do tempo. Além disso, a ideia de cidadãos críticos é inspirada em países de alto nível de educação e considerável nível de consolidação democrática. Em países com menor nível de educação e menos tradição de estabilidade democrática como o Brasil, é natural que os indivíduos não tenham o mesmo comprometimento com a democracia como ideia, nem a mesma capacidade de separar o conceito abstrato de democracia do desempenho real das instituições do regime. Por exemplo, Fuks, Casalecchi e Araújo (2017) questionam o uso desse conceito ao reportar que, segundo os dados do Barômetro das Américas de 2010, aproximadamente $72 \%$ dos insatisfeitos com a democracia nos Estados Unidos são críticos, enquanto no Brasil apenas $10 \%$ dos insatisfeitos são críticos.

O desenvolvimento de hipóteses que expliquem como os indivíduos desenvolvem maior ou menor confiança nas instituições políticas deve explicar quais grupos confiam mais ou quais confiam menos nas instituições. Explicações no nível macro, como a estabilidade do regime democrático e o desempenho econômico, são úteis para entender

\footnotetext{
${ }^{5}$ Argentina é frequentemente uma exceção a esse resultado, onde os níveis de confiança nas Forças Armadas são relativamente baixos.
} 
a percepção média de um país, mas são naturalmente limitadas para explicar a variação entre grupos de uma mesma população ${ }^{6}$. Para discutir as origens das opiniões dos cidadãos sobre as instituições políticas, este artigo se utiliza da perspectiva de aprendizagem da teoria social cognitiva para argumentar que experiências diretas e modelação vicária através das mídias, medidas pelo nível de engajamento político e consumo de informação, são fatores-chave no desenvolvimento dos níveis de confiança nas instituições.

\section{As percepções de confiança em nível pessoal}

A teoria social cognitiva é uma perspectiva em psicologia que postula que o comportamento humano é determinado, mantido e alterado por meio de relações recíprocas entre a pessoa, seu comportamento e o ambiente (Bandura, 1986). Um dos processos explicados por esse conjunto de relações é o da aprendizagem. Segundo essa perspectiva, os indivíduos aprendem por meio de experiência direta e por aprendizagem vicária, isto é, por meio da exposição a situações de modelação a partir da ação de outros. Ao longo de seu desenvolvimento pessoal, ao ter contato com situações e pessoas do seu meio próximo (e.g., familiares e grupos de amigos), os indivíduos adquirem padrões, valores e normas que são utilizados como guias que regulam suas escolhas e preferências (Bandura, 1986). Em uma versão mais recente desse modelo de aprendizagem, no caso, de aprendizagem política, Caprara e Vecchione (2017) descrevem que a socialização política depende de, pelo menos, três principais componentes. O primeiro componente é condutor para a aquisição de conhecimentos; o segundo, para a formação de atitudes e preferências políticas; e o terceiro, para a aquisição das competências necessárias para assumir um papel ativo no campo político, tais como participação em debates, persuasão e negociação. De forma geral, portanto, experiências pessoais e socialização com pessoas em ambientes políticos são os principais componentes na formação do conjunto de atitudes dos indivíduos.

Assim como as relações mais próximas, situações e pessoas mais distantes, como celebridades, políticos e atletas, também afetam a aquisição de valores e normas pessoais, pois servem de modelos positivos ou negativos para os indivíduos. Isto é, a mídia - TV, rádio, jornais, internet e redes sociais - é uma fonte de modelos para indivíduos e/ou grupos sociais, transformando valores e mudando comportamentos. Por exemplo, Singhal et al. (2004) apontam relatos em que dramas sociais em novelas veiculadas pela TV ou rádio, por exemplo, promoveram diversas mudanças de valores e práticas sociais mundo afora?. Assim, indivíduos desenvolvem atitudes sobre as instituições por meio de aprendizagem social através de contato com pessoas próximas ou por meio de modelos na mídia. Seguindo essa perspectiva, portanto, opiniões sobre instituições são reproduzidas

\footnotetext{
${ }^{6}$ Reconhece-se aqui que novos estudos que fazem uso de técnicas multiníveis analisam diferenças entre grupos e países concomitantemente.

7 Onuekwe (2015) relata como intervenções por meios de filmes e música aumentaram a eficácia de profissionais do campo da saúde.
} 
por meio de processo de aprendizagem para a grande maioria dos indivíduos, e não devido a avaliações independentes e diretas de cada cidadão. Ao destacar a importância da aprendizagem por meio de grupos e modelos midiáticos na formação de opiniões, a perspectiva da teoria social cognitiva se aproxima dos argumentos sociológicos da escola de Columbia (Lazarsfeld, Berelson e Gaudet, 1965) e psicológicos de Michigan (Campbell et al., 1960), mas difere na teorização sobre como a aquisição de valores se dá, pois ressalta os elementos fundamentais dos mecanismos de modelação social presentes na relação recíproca entre indivíduo e ambiente, como atenção, retenção, reprodução e motivação. Para uma discussão mais aprofundada sobre o processo de aprendizagem segundo a teoria social cognitiva, ver Bandura (1986). As implicações da perspectiva da teoria social cognitiva sobre a importância de experiências diretas e aprendizagem vicária para a aprendizagem social se alinham a resultados de estudos sobre confiança e formação de opiniões políticas no Brasil. De forma geral, a literatura indica que níveis de confiança em diferentes instituições estão relacionados ao tipo de socialização política, ao nível de escolaridade, às experiências com instituições e ao consumo de mídia (Colen, 2010; Silva e Beato, 2013; Silva e Ribeiro, 2016).

Estudos apontam que a convivência com modelos participativos na família e em ambiente escolar estimula a informação e a participação política (Rodrigues e Fuks, 2015; Fuks, 2011, 2012). Segundo Fuks (2012), a família e a escola são ambientes nos quais os jovens adquirem referências, informações, exemplos de valores, posicionamentos, a partir dos quais acabam selecionando e construindo a própria pauta de referências. Além do mais, Fuks (2012) acrescenta, para além da escolaridade e da participação dos pais e do ambiente escolar, a exposição à informação como variável que afeta diretamente o conhecimento político do jovem. Nesse sentido, o modelo apresentado pelo autor revela amplo diálogo com as considerações sobre a forma como a teoria social cognitiva explana a aprendizagem social e o papel das mídias como fonte adicional à interação direta na aquisição de informações e referenciais pessoais.

Em se tratando especificamente da confiança na instituição policial, Silva e Beato (2013) encontram que pessoas com maior idade confiam mais na instituição, enquanto pessoas com maior escolaridade possuem, na média, um nível de confiança menor em relação à polícia. Da mesma forma, Pinc (2006) complementa que a mídia é outra variável que influencia a confiança na polícia, pois, nos casos em que as ações negativas da polícia são amplamente divulgadas pelos noticiários, percebe-se uma diminuição do nível de confiança nessa instituição, fato observado em pesquisa realizada em 1997, logo após a divulgação do "caso da Favela Naval", em que policiais militares são filmados abordando, torturando e matando pessoas no meio da rua. Sobre outro grupo menos estudado, as pessoas que pertencem a comunidades religiosas ou que participam regularmente de reuniões que promovem interação face a face e assim induzindo à assimilação de normas e regras que promovem cooperação, a literatura aponta que estas confiam mais nas instituições (Moisés, 2005b; Silva e Beato, 2013). 


\section{Objetivo e dados}

O presente artigo tem como objetivos: 1) identificar variação nos níveis de confiança em diferentes instituições e entre a população em geral e as novas gerações; 2) mapear como os níveis de confiança em diferentes instituições se relacionam entre si; e 3) analisar até que ponto experiências diretas e exposição a modelos por meio de mídias influenciam os níveis de confiança dos jovens e da população brasileira nas instituições.

Parte das análises apresentadas a seguir usa dados das pesquisas de survey Barômetro das Américas 2014 e 2017 no Brasil ${ }^{8}$. Essas pesquisas foram conduzidas pelo Projeto de Opinião Pública da América Latina (Lapop, na sigla em inglês) e se utilizaram de um desenho amostral representativo probabilisticamente com seleção de respondentes igual a todos os indivíduos no país. A outra parte das análises se utiliza de dados da pesquisa "Jovens e política: discussões a partir da teoria social cognitiva", realizada no primeiro semestre de 2016, de acordo com orientações do comitê de ética da Unicamp em processo CAAE: 51531115.5.0000.54049 . Participaram do estudo 487 jovens estudantes do segundo e terceiro anos do ensino médio regular e do segundo, terceiro e quarto anos do ensino médio técnico integrado, de 11 escolas das redes pública e privada, segundo critérios de conveniência dos pesquisadores, como proximidade à cidade de Campinas e prévios contatos entre a equipe de pesquisa e funcionários dessas escolas. Todas as unidades de ensino se localizam no interior do estado de São Paulo e estão distribuídas entre seis municípios: Campinas, Indaiatuba, Paulínia, Sumaré, Hortolândia e Jundiaí.

Após a seleção das escolas públicas e privadas de ensino médio, foi realizado o primeiro contato com seus respectivos diretores para a apresentação da pesquisa e a solicitação de autorização para a realização desta. Em seguida à aprovação das autoridades competentes para a realização da investigação, foi feita uma apresentação da pesquisa aos alunos, numa visita às salas de aula, e a entrega do Termo de Consentimento Livre e Esclarecido (TCLE) a eles. Todos os alunos receberam duas vias do termo, uma do participante e outra do pesquisador. Através do TCLE, os participantes foram informados sobre: a instituição à qual a pesquisa e os pesquisadores estavam vinculados; os objetivos do estudo e sua relevância para a melhoria da convivência escolar; o caráter voluntário e sigiloso da sua participação; a utilização dos dados exclusivamente para fins de pesquisa acadêmica; a possibilidade de desistir dessa participação ao longo de sua realização; a ausência de riscos previsíveis; a ausência de despesas ou benefícios materiais associados com a pesquisa; e a disponibilidade constante do pesquisador responsável, para todos os esclarecimentos que se fizessem necessários.

\footnotetext{
8 Estes dados foram disponibilizados pelo Lapop (Latin American Public Opinion Project) da Vanderbilt University, que não tem nenhuma responsabilidade pela interpretação dos dados. As pesquisas do Barômetro das Américas são financiadas, em sua maior parte, pela Agência dos Estados Unidos para o Desenvolvimento Internacional (Usaid). Outras fontes importantes de apoio para a pesquisa de 2014 foram o Banco de Desenvolvimento Interamericano (IADB) e a Vanderbilt University. Para acesso aos dados e maiores informações sobre o projeto, veja <www.vanderbilt.edu/lapop>.

${ }^{9}$ Cópias da carta de consentimento informado podem ser encontradas no Apêndice C.
} 
Os estudantes com 18 anos ou mais interessados em participar da pesquisa puderam assinar o TCLE e devolvê-lo aos pesquisadores, enquanto os menores de 18 anos de idade levaram os termos para que fossem apreciados e assinados por seus pais ou responsáveis. Antes da realização da coleta de dados, os pesquisadores visitaram as escolas em busca dos TCLE dos estudantes menores de 18 anos. O preenchimento dos questionários ocorreu na presença dos pesquisadores. Em algumas escolas, os questionários foram apresentados em papel e, em outras, dependendo da disponibilidade de recursos informatizados da escola, foram apresentados online por meio de acesso a link disponibilizado pelos pesquisadores.

Em sua maior parte, o instrumento de coleta de dados da pesquisa com os jovens incluiu baterias de itens comuns ao Barômetro das Américas e também se baseou em outros temas trabalhados por outras pesquisas de opinião pública, como participação e eficácia política, confiança nas instituições, satisfação com a democracia e concordância com justificativas para definição de voto ${ }^{10}$. Assim como no estudo Barômetro das Américas, o tema da confiança nas instituições foi abordado em cinco questões mensuradas segundo uma escala em que o participante respondia às perguntas: "Até que ponto você tem confiança...?", assinalando seu nível de confiança nas instituições, considerando que 1 significava "nada" e 7 era sinônimo de "muita" confiança. Foram feitas perguntas sobre os sentimentos de confiança relacionados às três instituições inerentes ao processo democrático - eleições, Congresso Nacional e partidos políticos - e os relativos a duas instituições designadas ao policiamento e manutenção de ordem - Forças Armadas e Polícia Militar.

\section{Resultados}

Como primeiro passo na análise, avaliam-se os níveis médios de confiança em cada instituição que foi objeto de pergunta nas três pesquisas. A Figura 1 apresenta as médias e o intervalo de confiança das respostas para cada instituição por pesquisa, incluindo também valores independentes para o subgrupo dos mais jovens (16-25 anos) nas pesquisas nacionais do Barômetro das Américas ${ }^{11}$.

\footnotetext{
10 Perguntas do questionário analisadas aqui podem ser encontradas no Apêndice $A$.

11 As estatísticas com dados do Barômetro das Américas levam em conta o desenho multietápico de estratificação e conglomerados da amostra. As médias e os intervalos de confiança calculados com os da pesquisa "Jovens e política" foram ponderados de forma a balancear a distribuição por sexo e a intracorrelação de opiniões dos jovens de uma mesma escola.
} 
Figura 1

Nível de confiança por instituição e pesquisa

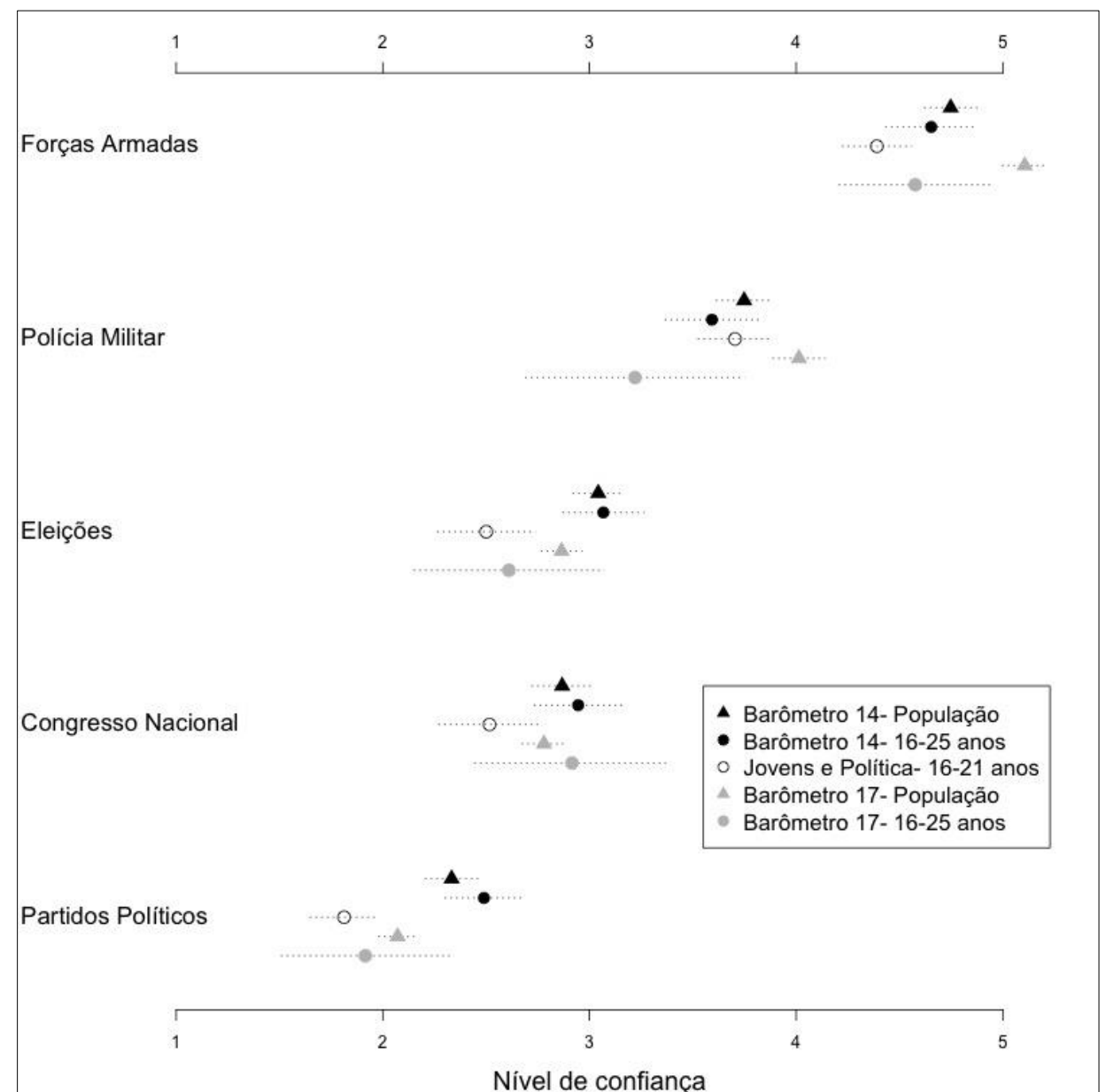

Fonte: Elaboração própria a partir dados do Barômetro das Américas Brasil 2014 e pesquisa original "Jovens e política".

Nota: Linhas pontilhadas representam o intervalo de $95 \%$ de confiança.

De forma semelhante a pesquisas anteriores no Brasil, a Figura 1 mostra que as Forças Armadas são, entre as instituições listadas, a que recebe maior confiança da população, seguida pela Polícia Militar. Por outro lado, as instituições inerentes a um regime de democracia representativa são vistas de forma mais negativa, especialmente os partidos políticos. Já em relação às diferenças nos níveis de confiança entre os jovens e a população em geral, os resultados são mistos. Se, por um lado, não há diferenças significativas entre os jovens e a população geral em 2014, em 2017 há um aumento no nível de confiança nas Forças Armadas e na Polícia Militar para a população em geral, mas uma leve queda entre os jovens. No entanto, essa diferença não se repete para as instituições de democracia representativa. Por fim, os jovens participantes na pesquisa 
"Jovens e política" indicaram um nível de confiança nas instituições políticas estatisticamente significativo mais baixo que a amostra nacional de 2014. Porém, a semelhança no nível de confiança nas Forças Armadas e Polícia Militar sugere que a diferença é produto dos acontecimentos políticos, e não devido a diferenças inerentes às amostras. Outro indicador desse resultado é que, com exceção da diferença no nível de confiança no Congresso Nacional, os valores médios de confiança dos jovens da região de Campinas se equiparam aos valores das respostas dos jovens na pesquisa nacional de $2017^{12}$. Portanto, os resultados indicam uma reprodução dos níveis de confiança entre os jovens em 2014, também reportado por Baquero e Gonzalez (2011) com dados de 2010. Mas em 2016 e 2017, os níveis de confiança nas instituições representativas caíram especialmente entre os mais jovens, enquanto houve uma divergência nas atitudes em relação às Forças Armadas e à Polícia Militar entre os jovens e o resto da população.

É importante ressaltar que o estudo com os jovens em 2016 e o estudo nacional em 2017 foram realizados em um período de mudanças significativas no cenário político brasileiro. Em 2016, as elites políticas recebiam grande pressão vinda das ruas através de manifestações contra o governo da então presidente do Brasil, Dilma Rousseff, que enfrentava um processo de impeachment, e a favor da operação da Polícia Federal denominada "Lava Jato", que começava a desmantelar um esquema de corrupção envolvendo inúmeras lideranças políticas. Já em 2017, o acordo da construtora Odebrecht com os investigadores apontava para o envolvimento dos principais partidos e políticos do país em casos de corrupção. Esses eventos passaram a fazer parte do cotidiano dos cidadãos devido à grande repercussão na mídia e nas redes sociais. Esse cenário difere bastante da pesquisa nacional Barômetro das Américas, feita no primeiro semestre de 2014, antes mesmo da reeleição da presidente Dilma Rousseff, da crise econômica e do avanço das investigações da operação que indiciariam tantos políticos. Assim, faz sentido que a volumosa exposição às informações sobre os atos indevidos cometidos pelos diversos partidos e políticos investigados tenha levado a uma redução nos níveis de confiança nos partidos políticos. Mas, se por um lado é altamente compreensível o descontentamento com a política no Brasil, por outro, o baixo nível de confiança nas instituições democráticas, inclusive nas eleições, não é um bom sinal para a democracia, considerando ainda que o nível de confiança nas Forças Armadas subiu nos últimos anos.

Apesar das notáveis diferenças entre os níveis de confianças nas instituições, a Figura 1 não indica a dimensionalidade das atitudes perante as diferentes instituições. Isto é, a descrição da distribuição por item não revela até que ponto há um fator comum entre as respostas aos diferentes itens. Com o objetivo de averiguar se os níveis de confiança nas diferentes instituições estão relacionados entre si, foi conduzida uma análise fatorial por eixos principais, a qual identifica fatores latentes representando a associação entre as respostas às perguntas relativas a confiança. Cada fator latente recebe um valor (chamado

\footnotetext{
12 De fato, resultados de análise do Barômetro das Américas no Brasil de 2014 indicam que não há diferenças entre respondentes de São Paulo e do resto do país.
} 
de eigenvalue) que condensa a variância da matriz de correlações. Quanto maior o eigenvalue, maior a variância entre os itens explicada pelo fator latente, levando assim a diferentes cargas fatoriais para cada item. Cargas fatoriais são análogas a um coeficiente padronizado de correlação entre os itens e o estimado fator latente. Portanto, quanto mais positiva a carga fatorial, maior a relação entre o item e o fator latente. A Tabela 1 mostra os resultados da análise de fatores com dados das três pesquisas, com o grupo de jovens das amostras nacionais separado:

Tabela 1

Análise fatorial dos itens sobre confiança nas instituições por pesquisa

\begin{tabular}{|c|c|c|c|c|c|c|c|c|c|c|}
\hline \multirow[b]{3}{*}{$\begin{array}{l}\text { Item } \\
\text { Confiança } \\
\text { na(s)/o(s)... }\end{array}$} & \multicolumn{4}{|c|}{ Barômetro das Américas 2014} & \multirow{2}{*}{\multicolumn{2}{|c|}{$\begin{array}{c}\begin{array}{c}\text { "Jovens e } \\
\text { política" } 2016\end{array} \\
\begin{array}{c}16-21 \text { anos } \\
(n=446)\end{array}\end{array}$}} & \multicolumn{4}{|c|}{ Barômetro das Américas 2017} \\
\hline & \multicolumn{2}{|c|}{$\begin{array}{l}\text { População } \\
(n=1466)\end{array}$} & \multicolumn{2}{|c|}{$\begin{array}{c}16-24 \text { anos } \\
(n=329)\end{array}$} & & & \multicolumn{2}{|c|}{$\begin{array}{c}\text { População } \\
(n=1503)\end{array}$} & \multicolumn{2}{|c|}{$\begin{array}{c}16-24 \text { anos } \\
(n=341)\end{array}$} \\
\hline & $\begin{array}{c}\text { Fator } 1 \\
\text { (eigen= } \\
1,94)\end{array}$ & $\begin{array}{c}\text { Fator } 2 \\
(\text { eigen }= \\
0,22)\end{array}$ & $\begin{array}{c}\text { Fator } 1 \\
(\text { eigen }= \\
1,82)\end{array}$ & $\begin{array}{c}\text { Fator } 2 \\
(\text { eigen }= \\
0,25)\end{array}$ & $\begin{array}{c}\text { Fator } 1 \\
(\text { eigen }= \\
1,43)\end{array}$ & $\begin{array}{c}\text { Fator } 2 \\
(\text { eigen }= \\
0,65)\end{array}$ & $\begin{array}{c}\text { Fator } 1 \\
\text { (eigen }= \\
1,86)\end{array}$ & $\begin{array}{c}\text { Fator } 2 \\
(\text { eigen }= \\
0,24)\end{array}$ & $\begin{array}{c}\text { Fator } 1 \\
(\text { eigen }= \\
2,14)\end{array}$ & $\begin{array}{c}\text { Fator } 2 \\
\text { (eigen }= \\
0,12)\end{array}$ \\
\hline Forças Armadas & 0,498 & 0,281 & 0,525 & 0,277 & 0,399 & 0,504 & 0,484 & 0,324 & 0,587 & 0,230 \\
\hline Polícia Militar & 0,631 & 0,210 & 0,560 & 0,223 & 0,475 & 0,434 & 0,593 & 0,224 & 0,644 & 0,143 \\
\hline Eleições & 0,644 & $-0,181$ & 0,653 & $-0,178$ & 0,511 & $-0,254$ & 0,607 & $-0,151$ & 0,669 & $-0,129$ \\
\hline $\begin{array}{l}\text { Congresso } \\
\text { Nacional }\end{array}$ & 0,687 & 0,008 & 0,685 & 0,026 & 0,645 & $-0,091$ & 0,677 & $-0,062$ & 0,723 & $-0,032$ \\
\hline $\begin{array}{l}\text { Partidos } \\
\text { políticos }\end{array}$ & 0,635 & $-0,254$ & 0,581 & $-0,296$ & 0,604 & $-0,363$ & 0,607 & $-0,151$ & 0,642 & $-0,182$ \\
\hline
\end{tabular}

Fonte: Elaboração própria a partir dos dados do Barômetro das Américas Brasil 2014 e 2017 e da pesquisa original "Jovens e política".

Nota: Os resultados não passaram por nenhum método de rotação para a apresentação de eigenvalue mais elevado para o primeiro fator. Mesmo quando a rotação de maximização da variância é executada, os eigenvalues do segundo fator não chegam a 1.

Os resultados das análises fatorais apontam para uma primeira dimensão que captura a propensão a ter confiança nas instituições de forma geral. Esse primeiro fator latente condensa importante parte da variância dos itens e é moderado ou altamente correlacionado positivamente com os cinco itens tanto nos dados do Barômetro das Américas quanto na pesquisa com os jovens. Os resultados também indicam uma segunda dimensão que diferencia mais as instituições militares das políticas. Apesar de esse fator não ser tão aparente quanto o primeiro, essa dimensão indica uma diferença entre a direção da confiança nas instituições designadas a garantir a ordem (Forças Armadas e Polícia Militar) e aquela nas instituições essenciais de uma democracia representativa, principalmente entre os mais jovens participantes da pesquisa de 2016.

Uma forma de verificar se essas dimensões capturam uma atitude difusa de adesão à democracia é compará-las a um item isolado que meça o apoio à democracia como regime. Essa análise também serve como teste para o debate sobre se os cidadãos que 
não confiam nas instituições têm maior apreciação pela democracia. Isto é, se desconfiar das instituições estiver, na média, ligado a maior adesão à democracia, como proposto pela literatura de cidadãos críticos (Norris, 1999), a associação entre o fator 1 e o item de apoio à democracia deveria ser negativo. Mas, se o desapreço pelas instituições estiver ligado à menor apreciação pela democracia, a relação média das variáveis deveria ser positiva.

Nas três pesquisas, participantes foram indagados sobre o valor de um regime democrático: "Mudando de assunto, a democracia tem alguns problemas, mas é melhor do que qualquer outra forma de governo. Até que ponto concorda com esta frase?". Respostas foram medidas usando a escala "Nada"-"Muito" de 7 pontos. Para uma mais fácil interpretação dos dados, os fatores gerados pela análise acima foram transformados em uma distribuição de $0-10$ e o fator 2 foi invertido para que a confiança nas instituições da democracia representativa fosse correlacionada positivamente com o fator ${ }^{13}$. Em vez de apresentar uma correlação entre as medidas, foram rodadas regressões lineares multivariadas (métodos de quadrados mínimos) que modelassem a variação de respostas ao item de apoio à democracia como função de características sociodemográficas (sexo, idade, religião, educação da mãe e etnia para as pesquisas nacionais) e dos fatores 1 e 2 . A Figura 2 apresenta o coeficiente não padronizado dos dois fatores por pesquisa:

\footnotetext{
${ }^{13}$ Estatísticas descritivas e um gráfico com a distribuição dos escores do fator é apresentado no Apêndice D Figura D3).
} 
Figura 2

Associação entre os fatores 1 e 2 e apoio à democracia

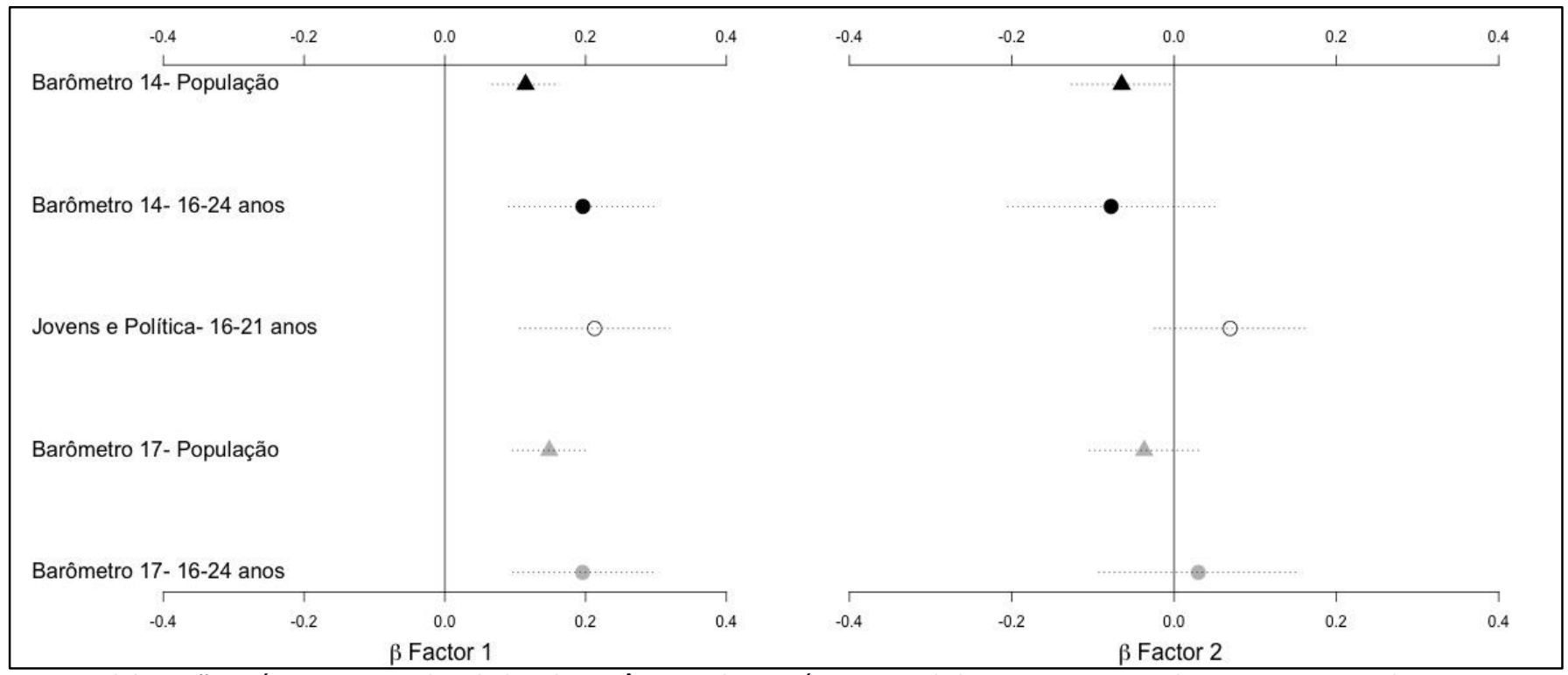

Fonte: Elaboração própria a partir dos dados do Barômetro das Américas Brasil de 2014 e 2017 e da pesquisa original "Jovens e política".

Nota: Linhas pontilhadas representam o intervalo de confiança para um $\alpha$ de 0,05.

O gráfico à esquerda na Figura 2 mostra a associação positiva entre a pergunta de apoio à democracia e o primeiro fator que captura o apoio latente às instituições. Esse resultado indica que, na média, aqueles que têm maior confiança nas instituições também reportam maior nível de apoio à democracia, o que contradiz a hipótese de que, entre a maioria dos indivíduos insatisfeitos com as instituições, há maior apoio à democracia. Já o gráfico à direita na Figura 2 indica que não há uma associação clara entre o nível de apoio à democracia e o fator latente 2. Ou seja, usando a pergunta direta sobre apoio à democracia como referência, o primeiro fator captura uma crença latente de apreço às instituições, enquanto o segundo fator, além de não ser tão robusto, também não está associado à preferência pela democracia.

Cabe aqui, então, entender melhor a origem desse primeiro fator gerado que mede a tendência geral em confiar ou não nas instituições. Para isso, regressões lineares são especialmente úteis, pois permitem examinar a relação independente de diferentes fatores pessoais com o fator latente de confiança nas instituições. Como discutido acima, experiências diretas e aprendizagem vicária por meio de modelos midiáticos são fundamentais para o desenvolvimento de crenças nas instituições. Experiências pessoais por meio da socialização com outros indivíduos em sociedade e consumo midiático proporcionam modelos pelos quais os indivíduos internalizam valores como confiança nas instituições. Assim, foram incluídas, no modelo explicativo do fator que mensura o apoio geral às instituições, variáveis binárias que indicam participação em grupos políticos e 
eficácia política interna e variáveis que descrevem o consumo de mídia (uso de internet e consumo de notícias) e as características sociodemográficas (sexo, idade, educação, religião). Em um segundo modelo, foram agregadas atitudes sobre o estado da economia, avaliações do desempenho do governo em relação à economia na análise dos dados de 2014 e desempenho do presidente na análise dos dados de 2017, e uma medida de confiança interpessoal ${ }^{14}$. Os dados utilizados aqui não informam especificidades sobre os canais de comunicação pelos quais os indivíduos recebem suas notícias, mas indicam medidas da frequência com que a população consome informação provinda de canais midiáticos e, no caso do estudo dos jovens, de quais tipos de mídia (televisão, internet, rádio). A Tabela 2 apresenta os resultados das regressões lineares para as pesquisas nacionais de 2014 e 2017, assim como modelos independentes para os respondentes entre 16 e 24 anos de idade:

\footnotetext{
${ }^{14}$ Enunciado, codificação de cada pergunta e estatísticas descritivas são apresentados nos Apêndices A e B.
} 
Tabela 2

Correlatos de confiança nas instituições, 2014 e 2017

\begin{tabular}{|c|c|c|c|c|c|c|c|c|}
\hline & \multicolumn{4}{|c|}{ Barômetro das Américas 2014} & \multicolumn{4}{|c|}{ Barômetro das Américas 2017} \\
\hline & \multicolumn{2}{|c|}{ População } & \multicolumn{2}{|c|}{16 a 24 anos } & \multicolumn{2}{|c|}{ População } & \multicolumn{2}{|c|}{16 a 24 anos } \\
\hline $\begin{array}{l}\text { Participação em } \\
\text { org. comunitária }\end{array}$ & $\begin{array}{l}0,167 \\
(0,104)\end{array}$ & $\begin{array}{c}0,135 \\
(0,083)\end{array}$ & $\begin{array}{c}0,370 \\
(0,240)\end{array}$ & $\begin{array}{c}0,375 \\
(0,229)\end{array}$ & $\begin{array}{l}0,181 * * \\
(0,073)\end{array}$ & $\begin{array}{c}0,191^{* *} \\
(0,077)\end{array}$ & $\begin{array}{c}0,092 \\
(0,144)\end{array}$ & $\begin{array}{c}0,285 * * \\
(0,142)\end{array}$ \\
\hline $\begin{array}{l}\text { Participação em } \\
\text { partido político }\end{array}$ & $\begin{array}{c}0,539 * * * \\
(0,137)\end{array}$ & $\begin{array}{c}0,371 * * * \\
(0,126)\end{array}$ & $\begin{array}{l}0,511 * * \\
(0,255)\end{array}$ & $\begin{array}{c}0,437^{*} * \\
(0,199)\end{array}$ & $\begin{array}{c}0,039 \\
(0,086)\end{array}$ & $\begin{array}{c}0,049 \\
(0,080)\end{array}$ & $\begin{array}{c}0,065 \\
(0,158) \\
\end{array}$ & $\begin{array}{c}0,074 \\
(0,146)\end{array}$ \\
\hline $\begin{array}{l}\text { Consumo de } \\
\text { notícias }\end{array}$ & $\begin{array}{l}-0,116 \\
(0,073)\end{array}$ & $\begin{array}{c}-0,078 \\
(0,057)\end{array}$ & $\begin{array}{c}-0,075 \\
(0,115) \\
\end{array}$ & $\begin{array}{c}0,062 \\
(0,106)\end{array}$ & $\begin{array}{c}-0,085 \\
(0,060)\end{array}$ & $\begin{array}{c}-0,071 \\
(0,056) \\
\end{array}$ & $\begin{array}{c}-0,093 \\
(0,097) \\
\end{array}$ & $\begin{array}{c}-0,064 \\
(0,100)\end{array}$ \\
\hline Uso de internet & $\begin{array}{c}-0,167 * * * \\
(0,047)\end{array}$ & $\begin{array}{l}-0,069 * \\
(0,039) \\
\end{array}$ & $\begin{array}{c}-0,279 * * * \\
(0,089)\end{array}$ & $\begin{array}{c}-0,179 * * \\
(0,075)\end{array}$ & $\begin{array}{c}-0,126 * * * \\
(0,048)\end{array}$ & $\begin{array}{c}-0,106 * * \\
(0,047)\end{array}$ & $\begin{array}{l}-0,221^{*} \\
(0,127)\end{array}$ & $\begin{array}{l}-0,193 \\
(0,128)\end{array}$ \\
\hline Eficácia interna & $\begin{array}{c}0,176 * * * \\
(0,036) \\
\end{array}$ & $\begin{array}{c}0,089 * * * \\
(0,026)\end{array}$ & $\begin{array}{c}0,242 * * * \\
(0,071)\end{array}$ & $\begin{array}{c}0,093 \\
(0,067) \\
\end{array}$ & $\begin{array}{c}0,197 * * * \\
(0,032)\end{array}$ & $\begin{array}{c}0,165^{* * *} * \\
(0,029)\end{array}$ & $\begin{array}{c}0,055 \\
(0,087) \\
\end{array}$ & $\begin{array}{c}0,094 \\
(0,075)\end{array}$ \\
\hline Sexo feminino & $\begin{array}{c}0,159 \\
(0,111)\end{array}$ & $\begin{array}{c}0,199 * * \\
(0,098)\end{array}$ & $\begin{array}{c}0,101 \\
(0,202)\end{array}$ & $\begin{array}{c}0,191 \\
(0,181)\end{array}$ & $\begin{array}{c}-0,205 \\
(0,125)\end{array}$ & $\begin{array}{c}0,051 \\
(0,112)\end{array}$ & $\begin{array}{c}-0,041 \\
(0,259)\end{array}$ & $\begin{array}{c}0,316 \\
(0,248)\end{array}$ \\
\hline Idade (em anos) & $\begin{array}{l}-0,008^{*} \\
(0,005)\end{array}$ & $\begin{array}{c}-0,003 \\
(0,004)\end{array}$ & $\begin{array}{c}-0,150 * * * \\
(0,045)\end{array}$ & $\begin{array}{c}-0,103 * * \\
(0,041)\end{array}$ & $\begin{array}{c}-0,005 \\
(0,005)\end{array}$ & $\begin{array}{l}-0,008^{*} \\
(0,004)\end{array}$ & $\begin{array}{c}-0,157 * * * \\
(0,052)\end{array}$ & $\begin{array}{c}-0,131 * * * \\
(0,046)\end{array}$ \\
\hline $\begin{array}{l}\text { Ensino } \\
\text { fundamental }\end{array}$ & $\begin{array}{c}-1,158^{* *} \\
(0,464)\end{array}$ & $\begin{array}{c}-0,753 * * \\
(0,332)\end{array}$ & . & & $\begin{array}{c}-0,213 \\
(0,462)\end{array}$ & $\begin{array}{c}-0,463 \\
(0,443)\end{array}$ & & . \\
\hline Ensino médio & $\begin{array}{c}-1,469 * * * \\
(0,470)\end{array}$ & $\begin{array}{c}-0,875 * * * \\
(0,333)\end{array}$ & $\begin{array}{c}-0,354 \\
(0,455)\end{array}$ & $\begin{array}{c}-0,282 \\
(0,411)\end{array}$ & $\begin{array}{c}-0,314 \\
(0,466)\end{array}$ & $\begin{array}{c}-0,652 \\
(0,454)\end{array}$ & $\begin{array}{c}0,144 \\
(0,322)\end{array}$ & $\begin{array}{c}0,131 \\
(0,309)\end{array}$ \\
\hline Ensino superior & $\begin{array}{c}-1,672 * * * \\
(0,498) \\
\end{array}$ & $\begin{array}{c}-1,096 * * * \\
(0,369) \\
\end{array}$ & $\begin{array}{c}-0,289 \\
(0,526)\end{array}$ & $\begin{array}{c}-0,542 \\
(0,507)\end{array}$ & $\begin{array}{c}-0,767 \\
(0,472) \\
\end{array}$ & $\begin{array}{c}-1,126 * * \\
(0,461) \\
\end{array}$ & $\begin{array}{c}-0,124 \\
(0,405)\end{array}$ & $\begin{array}{c}-0,220 \\
(0,432)\end{array}$ \\
\hline Católico & \multicolumn{8}{|c|}{ Referência } \\
\hline $\begin{array}{l}\text { Protestante trad. } \\
\text { / evangélico }\end{array}$ & $\begin{array}{c}0,026 \\
(0,194) \\
\end{array}$ & $\begin{array}{c}0,046 \\
(0,167) \\
\end{array}$ & $\begin{array}{c}-0,503 \\
(0,340) \\
\end{array}$ & $\begin{array}{l}-0,468^{*} \\
(0,257) \\
\end{array}$ & $\begin{array}{l}-0,308 * \\
(0,168) \\
\end{array}$ & $\begin{array}{l}-0,295^{*} \\
(0,149) \\
\end{array}$ & $\begin{array}{c}-0,531 \\
(0,360)\end{array}$ & $\begin{array}{c}-0,472 \\
(0,314) \\
\end{array}$ \\
\hline $\begin{array}{l}\text { Nenhuma } \\
\text { religião }\end{array}$ & $\begin{array}{c}-0,320 \\
(0,200)\end{array}$ & $\begin{array}{c}-0,014 \\
(0,197) \\
\end{array}$ & $\begin{array}{c}-0,372 \\
(0,417)\end{array}$ & $\begin{array}{c}-0,197 \\
(0,356)\end{array}$ & $\begin{array}{c}-0,636 * * * \\
(0,186) \\
\end{array}$ & $\begin{array}{c}-0,525^{* * *} \\
(0,164)\end{array}$ & $\begin{array}{c}-0,521 \\
(0,400)\end{array}$ & $\begin{array}{c}-0,171 \\
(0,374)\end{array}$ \\
\hline $\begin{array}{l}\text { Evangélica } \\
\text { pentecostal }\end{array}$ & $\begin{array}{c}-0,115 \\
(0,144) \\
\end{array}$ & $\begin{array}{c}0,003 \\
(0,123) \\
\end{array}$ & $\begin{array}{c}-0,449 \\
(0,280)\end{array}$ & $\begin{array}{c}-0,271 \\
(0,259)\end{array}$ & $\begin{array}{c}0,179 \\
(0,148) \\
\end{array}$ & $\begin{array}{c}0,107 \\
(0,139) \\
\end{array}$ & $\begin{array}{c}0,127 \\
(0,324) \\
\end{array}$ & $\begin{array}{c}0,143 \\
(0,297) \\
\end{array}$ \\
\hline Agnóstico / ateu & $\begin{array}{l}-0,719 * \\
(0,400) \\
\end{array}$ & $\begin{array}{c}-0,003 \\
(0,232)\end{array}$ & $\begin{array}{c}-1,048^{* *} \\
(0,415) \\
\end{array}$ & $\begin{array}{c}-0,212 \\
(0,389)\end{array}$ & $\begin{array}{c}-1,673 * * * \\
(0,359) \\
\end{array}$ & $\begin{array}{c}-1,167 * * * \\
(0,338) \\
\end{array}$ & $\begin{array}{c}-0,969 \\
(1,048)\end{array}$ & $\begin{array}{c}-0,614 \\
(0,922)\end{array}$ \\
\hline Outro & $\begin{array}{c}-0,936 * * * \\
(0,258)\end{array}$ & $\begin{array}{c}-0,723 * * * \\
(0,265) \\
\end{array}$ & $\begin{array}{c}-1,418^{* *} \\
(0,644) \\
\end{array}$ & $\begin{array}{l}-0,921 * \\
(0,527) \\
\end{array}$ & $\begin{array}{c}-0,368 \\
(0,249) \\
\end{array}$ & $\begin{array}{c}-0,310 \\
(0,226)\end{array}$ & $\begin{array}{c}-1,010^{* *} \\
(0,438) \\
\end{array}$ & $\begin{array}{c}-0,797 * * \\
(0,366) \\
\end{array}$ \\
\hline $\begin{array}{l}\text { Percepção da } \\
\text { economia } \\
\text { pessoal }\end{array}$ & & $\begin{array}{l}-0,092 \\
(0,067)\end{array}$ & & $\begin{array}{c}0,045 \\
(0,136)\end{array}$ & & $\begin{array}{l}-0,131^{*} \\
(0,067)\end{array}$ & & $\begin{array}{c}-0,284^{*} \\
(0,157)\end{array}$ \\
\hline $\begin{array}{l}\text { Confiança } \\
\text { interpessoal }\end{array}$ & & $\begin{array}{c}0,187 * * * \\
(0,065) \\
\end{array}$ & & $\begin{array}{c}0,016 \\
(0,113) \\
\end{array}$ & & $\begin{array}{c}0,317 * * * \\
(0,054) \\
\end{array}$ & & $\begin{array}{l}0,256 * \\
(0,138) \\
\end{array}$ \\
\hline $\begin{array}{l}\text { Avaliação do } \\
\text { governo federal } \\
\text { sobre a } \\
\text { economia }\end{array}$ & & $\begin{array}{c}0,626 * * * \\
(0,034)\end{array}$ & & $\begin{array}{c}0,598 * * * \\
(0,067)\end{array}$ & & . & & . \\
\hline $\begin{array}{l}\text { Avaliação do } \\
\text { presidente }\end{array}$ & & . & & . & & $\begin{array}{c}0,649 * * * \\
(0,053)\end{array}$ & & $\begin{array}{c}0,759 * * * \\
(0,107)\end{array}$ \\
\hline Intercepto & $\begin{array}{c}4,808^{* * * *} \\
(0,662)\end{array}$ & $\begin{array}{c}1,768 * * * \\
(0,571)\end{array}$ & $\begin{array}{c}6,813 * * * \\
(1,314)\end{array}$ & $\begin{array}{c}3,234 * * * \\
(1,164)\end{array}$ & $\begin{array}{c}4,348 * * * \\
(0,648)\end{array}$ & $\begin{array}{c}2,443 * * * \\
(0,596)\end{array}$ & $\begin{array}{c}7,952 * * * \\
(1,321) \\
\end{array}$ & $\begin{array}{c}, 619 * * * \\
(1,409)\end{array}$ \\
\hline $\begin{array}{l}\text { Número de } \\
\text { respondentes }\end{array}$ & 1435 & 1397 & 322 & 319 & 1451 & 1420 & 325 & 322 \\
\hline $\mathrm{R}^{2}$ (ajustado) & 0,090 & 0,329 & 0,142 & 0,334 & 0,075 & 0,207 & 0,086 & 0,243 \\
\hline
\end{tabular}

Fonte: Elaboração própria a partir dos dados do Barômetro das Américas, Brasil, 2014 e 2017.

Nota: Coeficientes não padronizados com os respectivos erros-padrão entre parênteses. Testes de VIF indicaram que nenhum valor chegou a 10. Significância: $* * * p<0,01, * * p<0,05, * p<0,10$. 
As regressões indicam que indivíduos que participaram de reuniões de partido político têm um nível de confiança mais elevado do que aqueles não ligados a partidos, embora essa diferença seja estatisticamente significativa apenas nos modelos de 2014 . O mesmo se repete entre aqueles que frequentam reuniões de comunidade ou bairro na pesquisa de 2017. Ainda que haja essa inversão no resultado de significância estatística entre os dois anos, de forma geral os coeficientes apontam para a relação positiva entre experiências pessoais com participação política e maior apreciação pelas instituições. Obviamente é difícil apontar causalidade nessa relação, pois é possível que tanto indivíduos que confiam nas instituições sejam mais propensos a participar de organizações quanto que aqueles que decidem participar de organizações tendem a desenvolver maior confiança nas instituições. Nesse mesmo sentido, indivíduos que têm maior confiança na sua compreensão de assuntos políticos, medida aqui pelo grau de eficácia interna, apresentam um nível de confiança maior nas instituições.

Já no sentido contrário, os dados indicam que aqueles que usam a internet com maior frequência tendem a confiar, na média, menos nas instituições, mesmo quando têm mesmo nível de educação. Embora também seja difícil atribuir causalidade, esse resultado indica que o uso da internet representa algo distinto em relação à percepção das instituições, tanto para a amostra de toda a população como para o grupo dos mais jovens das pesquisas nacionais. Por fim, as variáveis introduzidas no segundo modelo corroboram resultados anteriores de que percepção favorável do desempenho do governo (em relação à economia nos modelos de 2014, e ao presidente em 2017) e confiança interpessoal tendem a ser associados a maior nível de confiança nas instituições.

Na pesquisa com os estudantes da região metropolitana de Campinas, não houve perguntas sobre os itens agregados ao segundo modelo da Tabela 2. Entretanto, com os dados da pesquisa original, é possível distinguir a correlação entre diferentes tipos de mídia e confiança nas instituições, pois indagou-se sobre quais meios de comunicação os jovens utilizam para se informar. A Tabela 3 apresenta os dados da análise de regressão com as variáveis de participação política, consumo de notícias e características sociodemográficas: 
Tabela 3

Correlatos da confiança nas instituições, 2016

\begin{tabular}{|l|c|c|}
\hline & Coeficiente & (Erro-padrão) \\
\hline Participação em organização comunitária & 0,06 & $(0,14)$ \\
\hline Participação em partido político & $-0,09$ & $(0,13)$ \\
\hline Participação em audiência pública & $0,27^{* *}$ & $(0,06)$ \\
\hline Consumo de notícias via rádio & $0,27^{*}$ & $(0,14)$ \\
\hline Consumo de notícias via internet & $-0,48^{* *}$ & $(0,22)$ \\
\hline Consumo de notícias via televisão & 0,10 & $(0,23)$ \\
\hline Consumo de notícias via redes sociais & $-0,03$ & $(0,18)$ \\
\hline Índice de eficácia interna & $0,03^{* *}$ & $(0,01)$ \\
\hline Sexo feminino & $-0,25 * *$ & $(0,11)$ \\
\hline Questionário online (Papel=0) & 0,17 & $(0,16)$ \\
\hline Católico & \multicolumn{2}{|c|}{ Referência } \\
\hline Protestante tradicional / evangélico & $-0,10$ & $(0,25)$ \\
\hline Evangélica pentecostal & 0,44 & $(0,28)$ \\
\hline Nenhuma religião & $-0,14$ & $(0,22)$ \\
\hline Agnóstico / ateu & $-0,41$ & $(0,26)$ \\
\hline Outro & $-0,25$ & $(0,16)$ \\
\hline Intercepto & 2,47 & $(0,26)$ \\
\hline Número de respondentes & \multicolumn{2}{|c|}{0.07} \\
\hline R² (ajustado) & 422 \\
\hline
\end{tabular}

Fonte: Elaboração própria a partir de pesquisa original "Jovens e política". Nota: Coeficientes não padronizados (erros-padrão entre parênteses). Testes de VIF indicaram que nenhum valor chegou a 10. Significância: *** $p<0,01, * * p<0,05, * p<0,10$.

Assim como apontado nos dados da pesquisa nacional, jovens que apresentam maior crença no seu poder de compreensão dos assuntos políticos do país (eficácia interna) têm maior nível de confiança nas instituições. No entanto, participação em reuniões de partidos políticos ou de associações comunitárias não apresentam a mesma relação, o que não é surpreendente dada a idade dos participantes da pesquisa. Já quando perguntados sobre a frequência a audiências públicas dos órgãos políticos locais (prefeitura e Câmara dos Vereadores), jovens que foram a alguma audiência apresentam maior nível de confiança nas instituições, evidência a favor da relação entre socialização política e atitudes em favor das instituições.

Também conforme os resultados da análise com os dados do Barômetro das Américas, o uso da internet se apresenta como um fator que indica nível mais baixo de confiança nas instituições. Por sua vez, os jovens que disseram se utilizar do rádio como meio de comunicação para se informar sobre política apresentam, na média, nível de 
confiança mais alto do que aqueles que não o utilizam. Outros meios como televisão e redes sociais não oferecem diferenciação entre níveis de confiança. Essa relação entre os diferentes meios de comunicação utilizados e o nível de confiança merece maior atenção de pesquisadores, pois há a indicação de que o conteúdo oferecido pelos meios que servem de modelos parece ter um efeito importante nas opiniões dos jovens sobre as instituições ${ }^{15}$.

\section{Discussão}

Em um momento no qual o país vive uma crise política marcada por inúmeros escândalos de corrupção envolvendo todos os grandes partidos, a tradição de estudos de cultura política sugere que a preferência da população pela democracia, fundamentada na confiança nas instituições políticas, é crucial para a estabilidade do regime democrático. Por essa razão, é importante que cientistas políticos continuem avaliando o estado da opinião pública e buscando entender a organização e a origem das opiniões sobre as instituições, especialmente entre as novas gerações.

Neste artigo, busca-se entender quais instituições são vistas mais e menos positivamente, como as opiniões sobre diferentes instituições se relacionam, em que medida as atitudes dos jovens diferem da população em geral e como as experiências de socialização e o consumo de mídia afetam essas opiniões. Os resultados da pesquisa nacional Barômetro das Américas de 2014 e 2017 e a pesquisa original com 487 jovens de cidades do interior de São Paulo mostram que as instituições inerentes à democracia (i.e., eleições, partidos políticos e Congresso Nacional) são vistas de forma menos favorável que as instituições de ordem e policiamento (i.e., Forças Armadas e Polícia Militar). A diferença no nível de confiança entre esses dois grupos de instituições é especialmente grande para os entrevistados em 2016 e 2017, influenciados pelo contexto político marcado pela prisão de políticos e pelo aprofundamento nas investigações que escancararam um grande esquema de corrupção envolvendo governo, empresários, bancos públicos, empreiteiras e empresas estatais. Além do mais, os resultados da pesquisa com os jovens em 2016 e das análises de 2017 indicam que os níveis de confiança nas instituições políticas são ainda mais baixos entre as novas gerações. Assim, caso o desempenho das instituições não se altere, seguindo o conceito de reservatório de apoio de Easton $(1965,1975)$, é provável que a médio prazo os baixos níveis de confiança nas instituições democráticas possam levar a uma redução no comprometimento da população com a democracia, em outras palavras, a um aumento de reconhecimento de alternativas à democracia como possíveis soluções para problemas sociais. No entanto, ainda é necessário um maior volume de dados através do tempo para que se possa afirmar que essa diferença entre coortes é realmente produto de diferenças de gerações, como proposto por Foa e Mounk (2016,

\footnotetext{
15 É possível que esse resultado seja produto de um autoagrupamento (self-selection) de jovens com diferentes níveis de confiança nas instituições de acordo com a escolha dos meios de comunicação pelos quais preferem se informar.
} 
2017), ou simplesmente uma diferença em função da idade, como sugerido por Alexander e Welzel (2017), Norris (2017) e Voeten (2017).

A segunda análise apresentada aqui mostra que as atitudes sobre as instituições tendem a variar de forma conjunta, isto é, aqueles que reportam maior confiança em uma instituição tendem também a confiar mais nas outras. Isso não significa que não existam diferenças entre opiniões sobre as instituições, mas sim que, no uso da escala, os respondentes indicaram de forma consistente maior ou menor confiança nas diferentes instituições. Uma segunda dimensão oferecida pela análise fatorial indica uma diferenciação nas opiniões entre as instituições militares e as inerentes à democracia, entretanto esse fator latente tem baixo valor e não está correlacionado com respostas sobre a preferência acerca da democracia como o primeiro fator. Essa análise também indica que a nova interpretação de Norris (1999) e outros de que baixa confiança nas instituições pode estar ligada a maior adesão à democracia não se aplica, pelo menos na média, para aqueles que apresentam menor nível de confiança nas instituições no Brasil.

Finalmente, a terceira parte do artigo analisa os correlatos da dimensão que mede o maior nível de confiança nas instituições. Usando o modelo de aprendizagem da teoria social cognitiva como referência teórica, foi proposto que experiências políticas e consumo de mídia fossem fatores que estariam associados à variação dos níveis de confiança entre indivíduos. Na análise de regressões multivariadas dos dados do Barômetro das Américas, foi encontrado que prévias participações em organizações para o melhoramento da comunidade e organizações de partido político estão associadas a maiores níveis de confiança. Já nos dados da pesquisa com os jovens, enquanto o coeficiente indicando a relação entre participação em encontros de partidos políticos e confiança nas instituições não é estatisticamente significativo, o estimador da relação entre participação em audiência pública e confiança nas instituições é positivo e significativo. Esses resultados indicam, portanto, a importância da socialização como modelador de atitudes favoráveis às instituições. Seguindo esse resultado, maiores níveis de participação devem ser vistos como um bom sinal para a afirmação de valores democráticos.

Além do mais, as análises de regressão também indicaram o impacto negativo do consumo de notícias pela internet. Aqueles que consomem notícias dessa forma têm menor nível de confiança nas instituições, enquanto, entre os jovens, aqueles que consomem notícias por rádio tendem a ter maior nível de confiança. Esses resultados sugerem a importância que a mídia, por meio da exposição a situações e modelos, pode ter nas opiniões de cidadãos e jovens. No entanto, são necessários estudos que dediquem maior atenção à temporalidade e ao conteúdo das mídias para que haja maior clareza sobre quais são os mecanismos específicos que dão origem a essa relação' ${ }^{16}$.

\footnotetext{
16 Isto é, existe um impacto das mensagens dos canais de comunicação sobre os valores dos cidadãos, ou são as predisposições atitudinais dos indivíduos que os levam à busca de mídias específicas?
} 


\section{Referências bibliográficas}

AleXANDer, A. C.; Welzel, C. "Are people really turning away from democracy?". Journal of Democracy Online Exchange, Apr. 2017. Disponível em:

<https://www.journalofdemocracy.org/sites/default/files/media/Journal\%20of\%20Democracy\%20W eb\%20Exchange\%20-\%20Alexander\%20and\%20Welzel.pdf>. Acesso em: 1 maio 2018.

ANDERSON, C. Blaming the government: citizens and the economy in five European countries. Armonk, NY: M. E. Sharpe Press, 1995.

BANDURA, A. Social foundations of thought and action: a social cognitive theory. Englewood Cliffs, NJ: Prentice-Hall, 1986.

A teoria social cognitiva na perspectiva da agência. In: BANDURA, A.; AzzI, R. G.; Polydoro, S. A. J. (orgs.). Teoria social cognitiva: conceitos básicos. São Paulo: Artmed, 2008.

BAquero, M; Gonzalez, R. S. "Eleições, estabilidade democrática e socialização política no Brasil: análise longitudinal da persistência de valores nas eleições presidenciais de 2002 a 2010". Opinião Pública, vol. 17, no 2, p. 369-399, 2011. Disponível em:

$<$ http://www.scielo.br/scielo.php?script=sci_arttext\&pid=S0104-

62762011000200004\&lng=en\&nrm=iso > . Acesso em: 17 jan. 2017.

Booth, J. A.; Seligson, M. A. The legitimacy puzzle in Latin America: political support and democracy in eight nations. Cambridge: Cambridge University Press, 2009.

Campbell, A., et al. The American voter. New York/London: John Wiley \& Sons, 1960.

CAPRARA, G. V.; VeCCHIONe, M. Personalizing politics and realing democracy. New York: Oxford University Press, 2017. Disponível em:

<https://books.google.com.br/books?id=N9kWDgAAQBAJ\&pg=PT279\&lpg=PT279\&dq=Caprara, + G. V.,\&source $=$ bl\&ots $=$ CuJAErvcxt\&sig $=$ XexfNrrWu4U5kUWhADOKO0Z8eUk\&hl=ptBR\&sa =X\&ved=0ahUKEwiNvJHGrpHVAhUGDZAKHfgZBIkQ6AEIWDAI\#v=onepage\&q=Caprara, G.V.,\&f=true>. Acesso em: 9 set. 2017.

CARLIN, R. E. "The socioeconomic roots of support for democracy and the quality in Latin America". Revista Ciência Política. Santiago, vol. 26, no 1, p. 48-66, 2006. Disponível em: $<$ http://www.scielo.cl/scielo.php?script=sci_arttext\&pid=S0718090X2006000100003\&lng=es\&nrm=iso >. Acesso em: 9 set. 2017.

Ceobanu, A. M.; Wood, C. H.; Ribeiro, L. "Crime victimization and public support for democracy: evidence from Latin America". International Journal of Public Opinion Research, vol. 23, n 1 , p. 56$78,2010$.

Colen, C. M. L. "As covariantes da confiança política na América Latina". Opinião Pública, vol. 16, no 1, p. 1-27, 2010. Disponível em: <http://www.scielo.br/scielo.php?script=sci_arttext\&pid=S010462762010000100001\&lng=en\&nrm=iso>. Acesso em: 9 jan. 2017.

CORRAL, M. "(Mis)trust in political parties in Latin America". AmericasBarometer Insights, n 2, 2008. Disponível em: <https://www.vanderbilt.edu/lapop/insights/I0802en.pdf>. Acesso em: 1 maio 2018.

DAHL, R. Democracy and its critics. New Haven: Yale University Press, 1989.

DALTON, R. J. Political support in advanced industrial democracies. In: NorRIS, P. (ed.). Critical citizens: global support for democratic norms. Oxford: Oxford University Press, 1999. 
DiAmond, L. Developing democracy: toward consolidation. Baltimore: The Johns Hopkins University Press, 1999. Disponível em:

<https://books.google.com.br/books?id=sInqr5ILPE8C\&pg=PR3\&source=gbs_selected_pages\&redir _esc $=\mathrm{y} \# \mathrm{v}=$ onepage\&q\&; $=$ true $>$. Acesso em: 3 ago. 2017.

EASTON, D. The system analysis of political life. New York: Wiley, 1965.

"A re-assessment of the concept of political support". British Journal of Political Science, vol. 5, no 4; p. 435-57, 1975.

FOA, R. S.; Mounk, Y. "The danger of deconsolidation: the democratic disconnect". Journal of Democracy, vol. 27, no 3, p. 5-17, 2016. Disponível em:

<https://www.journalofdemocracy.org/sites/default/files/Foa\%26Mounk-27-3.pdf>. Acesso em: 1 maio 2018.

"The signs of deconsolidation". Journal of Democracy, vol. 28, no 1, p. 5-16, 2017. Disponível em: <https://www.journalofdemocracy.org/article/signs-deconsolidation>. Acesso em: 1 maio 2018.

FUKS, M. "Efeitos diretos, indiretos e tardios: trajetórias da transmissão intergeracional da participação política". Lua Nova, no 83, p. 145-178, 2011. Disponível em:

$<$ http://www.scielo.br/scielo.php?script=sci_arttext\&pid=S0102-

64452011000200006\&lng=pt\&nrm=iso >. Acesso em: 12 set. 2017.

"Atitudes, cognição e participação política: padrões de influência dos ambientes de socialização sobre o perfil político dos jovens". Opinião Pública, vol. 18, no 1, p. 88-108, 2012. Disponível em: <http://www.scielo.br/scielo.php?script=sci_arttext\&pid=S0104$62762012000100005 \&$ Ing $=p t \& n r m=$ iso $>$. Acesso em: 31 maio 2017.

FuKs, M.; CASAlecchi, G. A. Araújo, M. M. "Are dissatisfied democrats critical? Reevaluating the concept of the critical citizen?". Opinião Pública, Campinas, vol. 23, n 2, p. 316-333, 2017. Disponível em: <http://www.scielo.br/scielo.php?script=sci_arttext\&pid=S010462762017000200316\&lng=en\&nrm=iso\&tIng=en\#B11 >. Acesso em: 1 maio 2018.

Huntington, S. P. Political order in changing societies. New Haven: Yale University Press, 1968.

INGLEHART, R. Postmodernization erodes respect for authority, but increases support for democracy. In: NoRRIS, P. (ed.). Critical citizens: global support for democratic norms. Oxford: Oxford University Press, 1999.

KLINGEMANN, H. Mapping political support in the 1990s: a global analysis. In: NoRRIS, P. (ed.). Critical citizens: global support for democratic norms. Oxford: Oxford University Press, 1999.

LAZARSfeld, P.; Berelson, B.; Gaudet, H. The people's choice: how the voter makes up his mind in a presidential campaign. $2^{\text {a }}$ ed. New York: Columbia University Press, 1965.

Linz, J. J.; StePAn, A. Problems of democratic transition and consolidation: Southern Europe, South America, and post-communist Europe. Baltimore, MD: John Hopkins University Press, 1996.

LIPSET, S. M.; "Some social requisites of democracy: economic and political legitimacy". The American Political Science Review, vol. 53, no 1, p. 69-105, 1959. Disponível em:

<http://homepages.wmich.edu/ plambert/comp/lipset>. Acesso em: 18 set. 2017.

LOPES, D. M. N. N. "Para pensar a confiança e a cultura política na América Latina". Opinião Pública, Campinas, vol. 10, nº 1, p. 162-187, 2004. Disponível em:

$<$ http://www.scielo.br/scielo.php?script=sci_arttext\&pid=S0104-

62762004000100007\&lng=en\&nrm=iso >. Acesso em: 9 jan. 2017. 
Miller, A. H.; Listhaug, O. Political performance and institutional trust. In: NoRRIS, P. (ed.). Critical citizens: global support for democratic governance. New York: Oxford University Press, 1999.

MISHleR, W.; ROSE, R. "Support for parliaments and regimes in the transition toward democracy". Legislative Studies Quarterly, vol. 19, no 1, p. 5-32, 1994.

. "Trust, distrust and skepticism: popular evaluations of civil and political institutions in post-communist societies". Journal of Politics, vol. 59, n² 2, p. 418-451, 1997.

MoIsÉs, J. A. "A desconfiança nas instituições democráticas". Opinião Pública, vol. 11, no 1, p. $33-$ 63, 2005a. Disponível em: <http://www.scielo.br/scielo.php?script=sci_arttext\&pid=S0104$62762005000100002 \& \operatorname{lng}=$ en\&nrm=iso $>$. Acesso em: 9 jan. 2017.

. "Cidadania, confiança e instituições democráticas". Lua Nova, São Paulo, no 65, p. 7194, 2005b. Disponível em: <http://www.scielo.br/scielo.php?script=sci_arttext\&pid=S010264452005000200004\&lng=en\&nrm=iso >. Acesso em: 9 jan. 2017.

MonTALVo, D. "Do you trust your Armed Forces?". AmericasBarometer Insights, no 27, 2009. Disponível em: <http://www.vanderbilt.edu/lapop/insights/I0827en.pdf>. Acesso em: 15 set. 2017.

NoRRIS, P. The growth of critical citizens?. In: NoRRIS, P. (ed.). Critical citizens: global support for democratic norms. Oxford: Oxford University Press, 1999.

"Is Western democracy backsliding? Diagnosing the risks". Journal of Democracy Online Exchange, apr. 2017. Disponível em:

<https://www.journalofdemocracy.org/sites/default/files/media/Journal\%20of\%20Democracy\%20W eb\%20Exchange\%20-\%20Norris_0.pdf>. Acesso em: 1 maio 2018.

NORTH, D. C. "Institutions". Journal of Economic Perspectives, vol. 5, no 1, p. 97-112, 1991. Disponível em: <https://www.jstor.org/stable/1942704?seq=1\#page_scan_tab_contents>. Acesso em: 1 maio 2018.

ONUEKWE, C. E. Building polio vaccinators' self-efficacy and IPC skills: a field experiment with vaccinators' enter-educate polio training documentary in Northwest Nigeria. In: ONUEKWE, C. E. (ed.). Entertainment-education for health behaviour change: issues and perspective in Africa. Victoria, BC: Friesen Press, 2015.

Pinc, T. "O uso da força não-letal pela polícia nos encontros com o público". Dissertação de Mestrado. Departamento de Ciência Política da Universidade de São Paulo (USP), São Paulo, 2006.

RodRIGUES, G. A.; FUKS, M. "Grupos sociais e preferência política: o voto evangélico no Brasil". Revista Brasileira Ciências Sociais, vol. 30, no 87, p. 115-128, 2015. Disponível em: <http://www.scielo.br/scielo.php?script=sci_arttext\&pid=S010269092015000100115\&lng=pt\&nrm=iso $>$. Acesso em: 31 maio 2017.

Russo, G. "Em meio às crises no Brasil, respeito pelas instituições políticas é baixo e declinante". Barômetro das Américas: Actualidades, 1 de abril de 2016. Disponível em: <http://www.vanderbilt.edu/lapop/insights/ITB025po.pdf>. Acesso em: 18 dez. 2016.

SANTOS, M. L.; RochA, E. C. "Capital social e democracia: a confiança realmente importa?". Revista Sociologia Política, vol. 19, no 38, p. 43-64, 2011. Disponível em: <http://www.scielo.br/scielo.php?script=sci_arttext\&pid=S010444782011000100004\&lng=en\&nrm=iso >. Acesso em: 7 jan. 2017.

SELIGSON, M. A." The impact of corruption on regime legitimacy: a comparative study of four Latin American countries". Journal of Politics, vol. 64, no 2, p. 408-33, 2002. Disponível em: <https://onlinelibrary.wiley.com/doi/abs/10.1111/1468-2508.00132>. Acesso em: 1 maio 2018. 
"The rise of populism and the left in Latin America". Journal of Democracy, vol. 18, no 3, p. 81-95, 2007. Disponível em: <https://muse.jhu.edu/article/218823/pdf>. Acesso em: 1 maio 2018.

Seligson, M. A.; CARrión, J. F. "Political support, political skepticism, and political stability in new democracies: an empirical examination of mass support for coups d'Etat in Peru". Sage Journals, vol. 35, no 1, p. 58-82, 2002.

Silva, G. F.; BeAto, C. "Confiança na polícia em Minas Gerais: o efeito da percepção de eficiência e do contato individual". Opinião Pública, vol. 19, no 1, p. 118-153, 2013. Disponível em: <http://www.scielo.br/scielo.php?script=sci_arttext\&pid=S0104-62762013000100006>. Acesso em: 21 abr. 2016.

Silva, G. F.; CAMINHA, D. A. "A confiança nas instituições democráticas - vitimização por crimes violentos e confiança específica na polícia". $32^{\circ}$ Encontro Anual da Anpocs, 2012. Disponível em: <https://www.anpocs.com/index.php/papers-36-encontro/gt-2/gt02-2/7840-a-confianca-nasinstituicoes-democraticas-vitimizacao-por-crimes-violentos-e-confianca-especifica-na-policia/file $>$. Acesso em: 26 mar. 2016.

Silva, G. F.; Ribeiro, L. M. L. "Confiança nas instituições e vitimização por crime: qual a relação". Revista de Sociologia e Política, Curitiba, vol. 24, no 58, p. 59-84, 2016. Disponível em: <http://www.scielo.br/scielo.php?script=sci_arttext\&pid=S0104-44782016000200059>. Acesso em: 1 maio 2018.

Singhal, A., et al. (ed.). Entertainment-education and social change. Mahwah, NJ: Lawrence Erlbaum Associates, 2004.

Trevisan, F. "A Polícia Federal virou 'marca': a Polícia Federal adquire admiração similar à de marcas consagradas no imaginário popular e vira referência no país quando o assunto é combate à corrupção". Exame online, 11 abr. 2017. Disponível em: <http://exame.abril.com.br/blog/brandingconsumo-negocios/a-policia-federal-virou-marca/>. Acesso em: 8 ago. 2017.

VoETEN, E. "Are people really turning away from democracy?". Journal of Democracy Online Exchange, apr. 2017. Disponível em:

<https://www.journalofdemocracy.org/sites/default/files/media/Journal\%20of\%20Democracy\%20W eb\%20Exchange\%20-\%20Voeten_0.pdf>. Acesso em: 1 maio 2018.

WEIL, F. D. "The sources and structure of legitimation in Western democracies". American Sociological Review, vol. 54, n 5, p. 682-706, 1989.

ZeChmeister, E. J. (ed.). "The political culture of democracy in the Americas, 2014: democratic governance across 10 years of the AmericasBarometer". Lapop (Latin American Public Opinion Project). Nashville: Vanderbilt University, 2014. Disponível em:

<http://www.vanderbilt.edu/lapop/ab2014/AB2014_Comparative_Report_English_V3_revised_0113 15_W.pdf>. Acesso em: 9 set. 2017. 


\section{Apêndice A}

\section{Perguntas utilizadas - "Jovens e política"}

\section{Variável dependente}

[B] Agora você lerá uma série de questões sobre instituições políticas brasileiras. Vamos usar uma escala de 1 a 7 pontos, onde 1 significa NADA e 7 significa MUITA. Lembre-se que você pode usar qualquer número entre 1 e 7 . Até que ponto você tem confiança...

\begin{tabular}{|c|c|c|c|c|c|c|c|}
\hline & $\begin{array}{c}\text { Nada } \\
1 \\
\end{array}$ & 2 & 3 & 4 & 5 & 6 & $\begin{array}{c}\text { Muita } \\
7 \\
\end{array}$ \\
\hline [B12]...nas Forças Arm & & & & & & & \\
\hline [B13]...no Congresso & & & & & & & \\
\hline [B18]...na Polícia Milita & & & & & & & \\
\hline [B21]...nos partidos po & & & & & & & \\
\hline$[$ B47A $] \ldots$ nas eleições? & & & & & & & \\
\hline
\end{tabular}

[ING4] Mudando de assunto, a democracia tem alguns problemas, mas é melhor do que qualquer outra forma de governo. Até que ponto você concorda com esta frase?

\begin{tabular}{|c|c|c|c|c|c|c|}
\hline $\begin{array}{c}\text { Nada } \\
1\end{array}$ & 2 & 3 & 4 & 5 & 6 & \begin{tabular}{c} 
Muita \\
\hline
\end{tabular} \\
& & & & & & \\
\hline
\end{tabular}

[WWW1] Falando de outras coisas, com que frequência você usa a internet?

O Diariamente

O Algumas vezes por semana

O Algumas vezes ao mês

O Raramente

O Nunca

[COM] Quais desses veículos de comunicação você costuma utilizar para se informar sobre assuntos relacionados à política? (Selecione todas as opções que se aplicam.)

Televisão

Jornal ou Revista impressa

Rádio

Internet (portais de notícias)

Redes sociais (Facebook, Twitter)

Não costumo me informar sobre assuntos relacionados a política.

[CP] Por favor indique com qual frequência você assiste a reuniões de grupos e organizações. Use as seguintes frequências para responder: pelo menos uma vez por semana, uma ou duas vezes ao mês, uma ou duas vezes ao ano, ou nunca. 
GUILHERME A. RUSSO; ROBERTA GURGEL AZZI; CHARLENE FAVERI

\begin{tabular}{|c|c|c|c|c|}
\hline & $\begin{array}{c}\text { Uma vez por } \\
\text { semana }\end{array}$ & $\begin{array}{c}\text { Uma ou duas } \\
\text { vezes ao mês }\end{array}$ & $\begin{array}{c}\text { Uma ou duas } \\
\text { vezes ao ano }\end{array}$ & Nunca \\
\hline $\begin{array}{c}\text { [CP8] Reuniões de associação de bairro ou de } \\
\text { melhorias para a comunidade? Você assiste }\end{array}$ & & & & \\
\hline $\begin{array}{c}\text { [CP13] Reuniões de um partido ou movimento } \\
\text { político? Você assiste }\end{array}$ & & & & \\
\hline $\begin{array}{c}\text { [CP6] Reuniões de alguma organização } \\
\text { religiosa? Você assiste }\end{array}$ & & & & \\
\hline $\begin{array}{c}\text { [CP_MUN] Audiência pública da Câmara dos } \\
\text { Vereadores ou Prefeitura? Você assiste }\end{array}$ & & & & \\
\hline
\end{tabular}

Índice de eficácia interna

[SELFQUAL] Eu me considero bem qualificado(a) para participar na política.

O Concordo totalmente

O Concordo parcialmente

O Não concordo, nem discordo

O Discordo parcialmente

O Discordo totalmente

[UNDRSTND] Eu acredito ter um bom entendimento das questões políticas que afetam o nosso país.

O Concordo totalmente

O Concordo parcialmente

O Não concordo, nem discordo

O Discordo parcialmente

O Discordo totalmente

[EFF1] Os que governam o país se interessam pelo que pessoas como eu pensam.

O Concordo totalmente

O Concordo parcialmente

O Não concordo, nem discordo

O Discordo parcialmente

O Discordo totalmente

[OTHERS] Outras pessoas parecem ter mais facilidade para entender assuntos complicados que afetam o nosso país.

O Concordo totalmente

O Concordo parcialmente

O Não concordo, nem discordo

O Discordo parcialmente

O Discordo totalmente

[PUBOFF] Acredito que eu poderia fazer um trabalho, num cargo público, tão bom quanto a maioria das pessoas.

O Concordo totalmente

O Concordo parcialmente

O Não concordo, nem discordo

O Discordo parcialmente

O Discordo totalmente

[EFF1_LB] A maneira como as pessoas votam influencia muito o que acontece no Brasil.

O Concordo totalmente

O Concordo parcialmente

O Não concordo, nem discordo

O Discordo parcialmente

O Discordo totalmente 
[NOTSURE] Frequentemente, não me sinto seguro em falar de política com outras pessoas.

O Concordo totalmente

O Concordo parcialmente

O Não concordo, nem discordo

O Discordo parcialmente

O Discordo totalmente

[COMPLEX] Às vezes política e governo parecem tão complicados que uma pessoa como eu não consegue realmente entender o que está acontecendo.

O Concordo totalmente

O Concordo parcialmente

O Não concordo, nem discordo

O Discordo parcialmente

O Discordo totalmente

Demográficas

[SEXO] Para começar, qual é o seu sexo?

O Masculino

O Feminino

[IDADE] E qual é a sua idade? anos.

[Q3C] E qual a sua religião, se tiver?

O Católica

O Protestante tradicional ou evangélica não pentecostal

O Evangélica pentecostal (Qual?

O Nenhuma

O Sou ateu/Não acredito em Deus

O Outro

[ED2] E qual é o grau de escolaridade da sua mãe?

O Nenhum

O Ensino fundamental

O Ensino médio

O Ensino superior

[Q3C] E qual a sua religião, se tiver?

O Católica

O Protestante tradicional ou evangélica não pentecostal

O Evangélica pentecostal (Qual?

O Nenhuma

O Sou ateu/Não acredito em Deus

O Outro

Perguntas - Barômetro das Américas 2014, 2017 (enunciado diferente)

[WWW1] Falando de outras coisas, com que frequência você usa a Internet?

O Diariamente

O Algumas vezes por semana

O Algumas vezes ao mês

O Raramente

O Nunca 
[GI0] Com que frequência você presta atenção às notícias, seja na TV, rádio, jornais ou na Internet?

O Diariamente

O Algumas vezes por semana

O Algumas vezes ao mês

O Raramente

O Nunca

[Q2Y] Em que ano o(a) sr./sra. nasceu? ano

[EFF2] $O(A)$ sr./sra. sente que entende bem os assuntos políticos mais importantes do país. Até que ponto concorda ou discorda desta frase?

Anotar o número $1-7,88=$ NS $98=$ NR

[ED] Qual foi o último ano de escola que o(a) sr./sra. terminou Ano do universitário) $=$ (primário, secundário, universidade, superior não-

[Q3C] Qual a sua religião, se tiver? [Não leia as alternativas.]

[Se o entrevistado diz que não tem religião, explore para escolher se o entrevistado pertence à alternativa 4 ou 11.]

(1) Católica

(2) Protestante tradicional ou evangélica não pentecostal (Adventista, Batista, Calvinista, Luterano, Metodista, Presbiteriano, Anglicano, Episcopal, Discípulo de Cristo)

(3) Outra não cristã (Muçulmano, Budista, Induísta, Taoísta, Confuciano, Baha'i)

(4) Nenhuma (Acredita em uma entidade suprema mas não pertence à religião nenhuma.)

(5) Evangélica pentecostal (Pentecostal, Igreja Universal, Sara Nossa Terra, Igreja Quadrangular,

Congregação Cristã, Adventista do Sétimo Dia, Igreja Cristã Reformada, Adventista, Adventista de

Sétimo Dia etc.)

(6) Igreja de Jesus Cristo dos Santos dos Últimos Dias ou SUD (Mórmon)

(7) Religiões tradicionais ou nativas (Candomblé, Umbanda, Voodoo, Rastafari, religiões mayas, Santo Daime, esotérica)

(8) Espírita kardecista

(10) Judeu (ortodoxo, reforma, conservador)

(11) É agnóstico ou ateu/Não acredita em Deus

(12) Testemunha de Jeová

(88) NS

(98) NR

[IT1] Agora, falando das pessoas daqui, o(a) sr./sra. diria que as pessoas daqui são muito confiáveis, algo confiáveis, pouco confiáveis, nada confiáveis?

(1) Muito confiáveis, (2) Algo confiáveis, (3) Pouco confiáveis, (4) Nada confiáveis

[IDIO2]. O(A) sr./sra. acha que sua atual situação econômica está melhor, igual ou pior que a de há doze meses?

(1) Melhor, (2) Igual, (3) Pior, (88) Não sabe, (98) Não respondeu

(2014) [N15]. Até que ponto o(a) sr./sra. diria que o atual governo federal está gerenciando bem a economia?

Anotar o número $1-7,88=$ NS $98=$ NR

(2017) [M1] Falando em geral do atual governo, como o(a) sr./sra. avalia o trabalho que o presidente Michel Temer está realizando [Leia as alternativas.]

(1) Muito bom, (2) Bom, (3) Nem bom, nem mau (regular)

(4) Mau, (5) Muito mau (péssimo) 
CONFIANÇA NAS INSTITUIÇÕES POLÍTICAS: DIFERENÇAS E INTERDEPENDÊNCIA NAS OPINIÕES DE JOVENS E POPULAÇÃO

\section{Apêndice B}

Tabela B1

Estatísticas descritivas - Barômetro das Américas, 2014

\begin{tabular}{|c|c|c|c|c|c|}
\hline Variável & Observações & Média & Desvio-padrão & Mín. & Máx. \\
\hline Fator (variável dependente) & 1466 & 3.69 & 2.22 & 0 & 10 \\
\hline Reuniões, melhoria da comunidade & 1492 & 1.26 & 0.65 & 1 & 4 \\
\hline Reuniões, partido político & 1491 & 1.13 & 0.43 & 1 & 4 \\
\hline Atenção às notícias & 1500 & 4.57 & 0.84 & 1 & 5 \\
\hline Uso de internet & 1500 & 3.00 & 1.81 & 1 & 5 \\
\hline Eficácia interna & 1495 & 3.58 & 1.78 & 1 & 7 \\
\hline Sexo $($ Feminino $=2)$ & 1500 & 1.50 & 0.50 & 1 & 2 \\
\hline Idade & 1500 & 39.63 & 16.23 & 16 & 89 \\
\hline Educação primária & 1498 & 0.30 & 0.46 & 0 & 1 \\
\hline Educação secundária & 1498 & 0.57 & 0.50 & 0 & 1 \\
\hline Educação superior & 1498 & 0.09 & 0.29 & 0 & 1 \\
\hline Educação da mãe & 1258 & 1.72 & 1.82 & 0 & 8 \\
\hline Protestante (tradicional) & 1482 & 0.11 & 0.31 & 0 & 1 \\
\hline Nenhuma & 1482 & 0.08 & 0.26 & 0 & 1 \\
\hline Evangélico pentecostal & 1482 & 0.20 & 0.40 & 0 & 1 \\
\hline $\begin{array}{l}\text { Agnóstico, ateu / Não acredito em } \\
\text { Deus }\end{array}$ & 1482 & 0.01 & 0.12 & 0 & 1 \\
\hline Outro & 1482 & 0.03 & 0.18 & 0 & 1 \\
\hline Percepção da economia pessoal & 1493 & 1.90 & 0.74 & 1 & 3 \\
\hline Confiança interpessoal & 1476 & 2.59 & 0.89 & 1 & 4 \\
\hline $\begin{array}{l}\text { Avaliação do governo federal sobre a } \\
\text { economia }\end{array}$ & 1478 & 3.09 & 1.72 & 1 & 7 \\
\hline
\end{tabular}

Fonte: Elaboração própria a partir de dados do Barômetro das Américas (Brasil, 2014). 
Tabela B2

Estatísticas descritivas - "Jovens e política", 2016

\begin{tabular}{|c|c|c|c|c|c|}
\hline Variável & Observações & Média & Desvio-padrão & Mín. & Máx. \\
\hline Fator (variável dependente) & 446 & 2.86 & 1.48 & 0 & 10 \\
\hline Reuniões, melhoria da comunidade & 459 & 1.31 & 0.67 & 1 & 4 \\
\hline Reuniões, partido político & 456 & 1.67 & 0.90 & 1 & 4 \\
\hline Reuniões, audiência pública & 459 & 1.49 & 0.80 & 1 & 4 \\
\hline Uso rádio & 463 & 0.21 & 0.41 & 0 & 1 \\
\hline Uso internet & 463 & 0.79 & 0.41 & 0 & 1 \\
\hline Uso televisão & 463 & 0.76 & 0.42 & 0 & 1 \\
\hline Uso redes sociais & 463 & 0.64 & 0.48 & 0 & 1 \\
\hline Índice de eficácia interna & 466 & 10.93 & 3.73 & 1 & 21 \\
\hline Feminino & 487 & 0.61 & 0.49 & 0 & 1 \\
\hline Educação da mãe & 459 & 3.21 & 0.76 & 1 & 4 \\
\hline Modo (Papel = 1) & 493 & 1.38 & 0.48 & 1 & 2 \\
\hline Protestante (tradicional) & 453 & 0.14 & 0.35 & 0 & 1 \\
\hline Evangélico & 453 & 0.08 & 0.27 & 0 & 1 \\
\hline Nenhuma religião & 453 & 0.14 & 0.34 & 0 & 1 \\
\hline Ateu/Não acredito em Deus & 453 & 0.08 & 0.27 & 0 & 1 \\
\hline Outro & 453 & 0.13 & 0.34 & 0 & 1 \\
\hline
\end{tabular}

Fonte: Elaboração própria a partir de pesquisa original "Jovens e política". 
CONFIANÇA NAS INSTITUIÇÕES POLÍTICAS: DIFERENÇAS E INTERDEPENDÊNCIA NAS OPINIÕES DE JOVENS E POPULAÇÃO

Tabela B3

Estatísticas descritivas - Barômetro das Américas, 2017

\begin{tabular}{|c|c|c|c|c|c|}
\hline Variável & Observações & Média & Desvio-padrão & Mín. & Máx. \\
\hline Fator (variável dependente) & 1503 & 3.69 & 2.17 & 0 & 10 \\
\hline Reuniões, melhoria da comunidade & 1523 & 1.36 & 0.74 & 1 & 4 \\
\hline Reuniões, partido político & 1520 & 1.37 & 0.79 & 1 & 4 \\
\hline Atenção às notícias & 1529 & 4.31 & 1.10 & 1 & 5 \\
\hline Uso de internet & 1532 & 3.69 & 1.68 & 1 & 5 \\
\hline Eficácia interna & 1521 & 3.79 & 1.81 & 1 & 7 \\
\hline Sexo (Feminino $=2$ ) & 1532 & 1.50 & 0.50 & 1 & 2 \\
\hline Idade & 1532 & 38.59 & 15.57 & 16 & 86 \\
\hline Educação primária & 1532 & 0.38 & 0.49 & 0 & 1 \\
\hline Educação secundária & 1532 & 0.48 & 0.50 & 0 & 1 \\
\hline Educação superior & 1532 & 0.12 & 0.33 & 0 & 1 \\
\hline Educação da mãe & 1098 & 2.06 & 1.98 & 0 & 8 \\
\hline Protestante (tradicional) & 1506 & 0.10 & 0.31 & 0 & 1 \\
\hline Nenhuma & 1506 & 0.08 & 0.26 & 0 & 1 \\
\hline Evangélico pentecostal & 1506 & 0.22 & 0.41 & 0 & 1 \\
\hline $\begin{array}{l}\text { Agnóstico, ateu / Não acredito em } \\
\text { Deus }\end{array}$ & 1506 & 0.01 & 0.12 & 0 & 1 \\
\hline Outro & 1506 & 0.07 & 0.26 & 0 & 1 \\
\hline Percepção da economia pessoal & 1529 & 2.28 & 0.76 & 1 & 3 \\
\hline Confiança interpessoal & 1500 & 2.40 & 0.94 & 1 & 4 \\
\hline $\begin{array}{l}\text { Avaliação do governo federal sobre a } \\
\text { economia }\end{array}$ & 1522 & 2.20 & 1.10 & 1 & 5 \\
\hline
\end{tabular}

Fonte: Elaboração própria a partir de dados do Barômetro das Américas (Brasil, 2017). 


\section{Apêndice C}

\section{Cartas de consentimento informado}

\section{TERMO DE CONSENTIMENTO UVRE E ESCLARECIDO \\ Jovens e Política: Discussões a partir da Teoria Social Cognitiva \\ Coordenadores responsáveis: Dra. Roberta Gurgel Azzi e Guilherme Russo Número do CAAE: 51531115.5 .0000 .5404}

Você está sendo convidado a participar como voluntário de uma pesquisa. Este documento, chamado Termo de Consentimento Livre e Esclarecido, visa assegurar seus direitos como participante e é elaborado em duas vias, uma que deverá ficar com você e outra com o pesquisador.

Por favor, leia com atenção e calma, aproveitando para esclarecer suas dúvidas. Se houver perguntas antes ou mesmo depois de assiná-lo, você poderá esclarecê-las com o pesquisador. Se preferir, pode levar este termo para casa e consultar seus familiares ou outras pessoas antes de decidir participar. Não haverá nenhum tipo de penalização ou prejuízo se você não aceitar participar ou retirar sua autorização em qualquer momento.

Justificativa e objetivos:

Esta pesquisa está inserida nas ações do "Núcleo de Estudos Avançados em Psicologia Cognitiva Comportamental" da Faculdade de Educação da UNICAMP e tem como objetivo conhecer a percepção dos alunos do ensino médio sobre aspectos formativos e participativos a respeito de questões políticas nacionais. Tal pesquisa se justifica para a maior participação e representatividade no regime democrático brasileiro.

\section{Procedimentos:}

Participando do estudo você está sendo convidado a preencher os seguintes instrumentos: 1) Questionário sobre Autoeficácia Política; 2) Questionário sobre atitudes sobre instituições e atual cenário político-econômico; 3) Questionário sobre experiências prévias com a política; 4) Questionário sobre conhecimento político; 5) Questionário demográfico; 6) Instrumento sobre engajamento cognitivo e 7) Questionário sobre Desengajamento Moral. A estimativa de tempo necessário para o preenchimento dos instrumentos é de $\mathbf{5 0}$ (cinquenta) minutos.

\section{Desconfortos e riscos:}

A presente pesquisa não apresenta riscos previsiveis ou passíveis de prevenção. Ressalta-se que a estimativa de tempo necessária para o preenchimento de todos os instrumentos é de 50 (cinquenta) minutos.

\section{Beneficios:}

A sua participação não trará nenhum tipo de beneficio pessoal, mas auxiliará na posterior elaboração de uma intervenção educacional, a qual poderá trazer beneficios à sociedade em geral.

Sigilo e privacidade:

Você tem a garantia de que sua identidade será mantida em sigilo e nenhuma informação será dada a outras pessoas que não façam parte da equipe de pesquisadores. Na divulgação dos resultados desse estudo, seu nome não será citado.

Ressarcimento e Indenização:

A participação na pesquisa é voluntária. Não haverá ressarcimento de qualquer tipo de despesa, já que com a participação na pesquisa não há gasto, sendo realizada durante a rotina de estudo do aluno. Além disso, é importante esclarecer que não haverá prejuizos para quem se recusar a participar.

Rubrica do pesquisador:

Rubrica do participante: 


\section{TERMO DE CONSENTIMENTO UVRE E ESCLARECIDO \\ Jovens e Política: Discussões a partir da Teoria Social Cognitiva \\ Coordenadores responsáveis: Dra. Roberta Gurgel Azzi e Guilherme Russo Número do CAAE: 51531115.5.0000.5404}

Você está sendo convidado a participar como voluntário de uma pesquisa. Este documento, chamado Termo de Consentimento Livre e Esclarecido, visa assegurar seus direitos como participante e é elaborado em duas vias, uma que deverá ficar com você e outra com o pesquisador.

Por favor, leia com atenção e calma, aproveitando para esclarecer suas dúvidas. Se houver perguntas antes ou mesmo depois de assiná-lo, você poderá esclarecê-las com o pesquisador. Se preferir, pode levar este termo para casa e consultar seus familiares ou outras pessoas antes de decidir participar. Não haverá nenhum tipo de penalização ou prejuízo se você não aceitar participar ou retirar sua autorização em qualquer momento.

Justificativa e objetivos:

Esta pesquisa está inserida nas ações do "Núcleo de Estudos Avançados em Psicologia Cognitiva Comportamental" da Faculdade de Educação da UNICAMP e tem como objetivo conhecer a percepção dos alunos do ensino médio sobre aspectos formativos e participativos a respeito de questões políticas nacionais. Tal pesquisa se justifica para a maior participação e representatividade no regime democrático brasileiro.

\section{Procedimentos:}

Participando do estudo você está sendo convidado a preencher os seguintes instrumentos: 1) Questionário sobre Autoeficácia Política; 2) Questionário sobre atitudes sobre instituições e atual cenário político-econômico; 3) Questionário sobre experiências prévias com a política; 4) Questionário sobre conhecimento político; 5) Questionário demográfico; 6) Instrumento sobre engajamento cognitivo e 7) Questionário sobre Desengajamento Moral. A estimativa de tempo necessário para o preenchimento dos instrumentos é de 50 (cinquenta) minutos.

\section{Desconfortos e riscos:}

A presente pesquisa não apresenta riscos previsíveis ou passíveis de prevenção. Ressalta-se que a estimativa de tempo necessária para o preenchimento de todos os instrumentos é de 50 (cinquenta) minutos.

\section{Benefícios:}

A sua participação não trará nenhum tipo de beneficio pessoal, mas auxiliará na posterior elaboração de uma intervenção educacional, a qual poderá trazer beneficios à sociedade em geral.

Sigilo e privacidade:

Você tem a garantia de que sua identidade será mantida em sigilo e nenhuma informação será dada a outras pessoas que não façam parte da equipe de pesquisadores. Na divulgação dos resultados desse estudo, seu nome não será citado.

Ressarcimento e Indenização:

A participação na pesquisa é voluntária. Não haverá ressarcimento de qualquer tipo de despesa, já que com a participação na pesquisa não há gasto, sendo realizada durante a rotina de estudo do aluno. Além disso, é importante esclarecer que não haverá prejuizos para quem se recusar a participar.

Rubrica do pesquisador: Rubrica do participante: 


\section{Apêndice D}

Tabelas extras - Barômetro das Américas 2014

\section{Tabela D1}

Estatísticas descritivas dos itens sobre confiança nas instituições

\begin{tabular}{|lccc|}
\hline Instituição & Média & Desvio-padrão & Respondentes \\
Forças Armadas & 4,76 & 1,93 & 1.490 \\
Polícia Militar & 3,76 & 1,96 & 1.496 \\
Congresso Nacional & 2,87 & 1,84 & 1.491 \\
Eleições & 3,04 & 1,87 & 1.491 \\
Partidos políticos & 2,33 & 1,63 & 1.492 \\
\hline
\end{tabular}

Fonte: Elaboração própria a partir do Barômetro das Américas (Brasil, 2014).

Tabela D2

Diferenças entre as médias dos itens sobre confiança nas instituições

\begin{tabular}{|lcccc|}
\hline Instituição & $\begin{array}{c}\text { Forças } \\
\text { Armadas }\end{array}$ & Polícia Militar & $\begin{array}{c}\text { Congresso } \\
\text { Nacional }\end{array}$ & Eleições \\
Polícia Militar & $1,00(18,95)^{*}$ & & & \\
Congresso Nacional & $1,89(34,16)^{*}$ & $0,88(17,10)^{*}$ & & \\
Eleições & $1,71(28,57)^{*}$ & $0,71(12,95)^{*}$ & $-0,17(3,35)^{*}$ & \\
Partidos políticos & $2,42(41,47)^{*}$ & $1,41(25,89)^{*}$ & $0,54(11,65)^{*}$ & $0,70(16,12)^{*}$ \\
\hline
\end{tabular}

Fonte: Elaboração própria a partir do Barômetro das Américas (Brasil, 2014).

Nota: Diferença entre variável da coluna e linha, valor t em parênteses. Significância: * $p<0,05$.

\section{Tabela D3}

Correlações entre os itens sobre confiança nas instituições

\begin{tabular}{|lcccc|}
\hline Instituição & $\begin{array}{c}\text { Forças } \\
\text { Armadas }\end{array}$ & Polícia Militar & $\begin{array}{c}\text { Congresso } \\
\text { Nacional }\end{array}$ & $\begin{array}{c}\text { Partidos } \\
\text { políticos }\end{array}$ \\
Forças Armadas & 1 & 1 & & \\
Polícia Militar & 0,451 & 0,465 & 1 & 1 \\
Congresso Nacionãos & 0,370 & 0,436 & 0,394 & 0,534 \\
Partidos políticos & 0,263 & 0,489 & 0,330 & 1 \\
\hline
\end{tabular}

Fonte: Elaboração própria a partir do Barômetro das Américas (Brasil, 2014). 
Figura D1

Distribuição dos escores do fator 1 - Barômetro das Américas, 2014

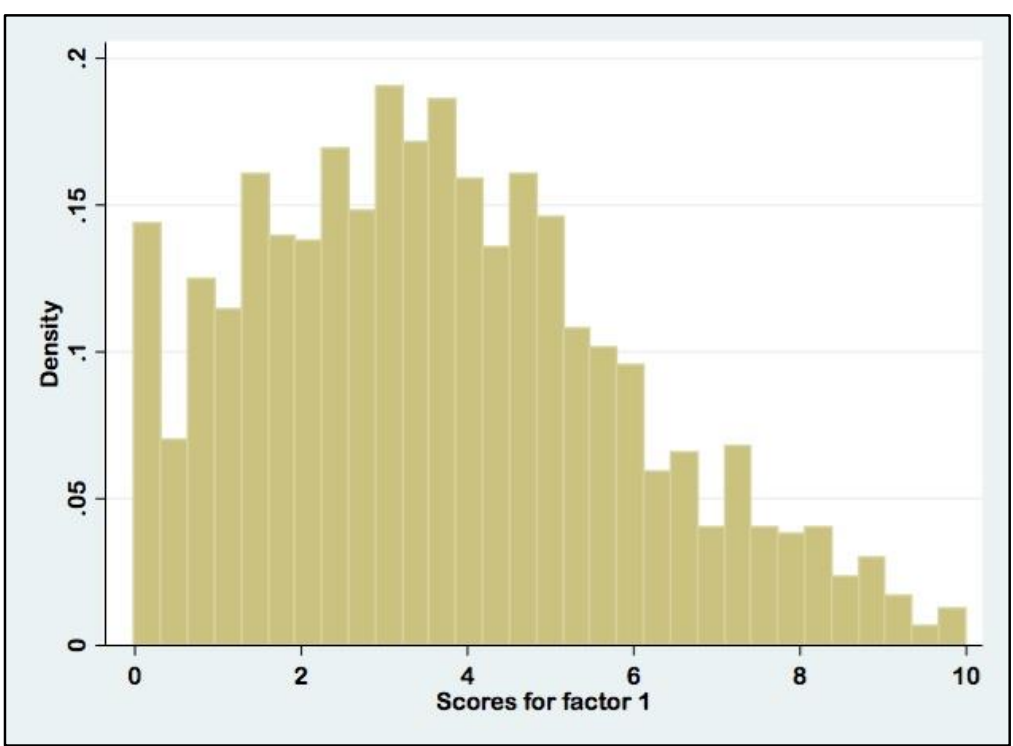

Fonte: Elaboração própria a partir do Barômetro das Américas (Brasil, 2014).

Tabelas extras - "Jovens e política"

Tabela D4

Estatísticas descritivas dos itens sobre confiança nas instituições

\begin{tabular}{|lccc|}
\hline Instituição & Média & Desvio-padrão & Respondentes \\
Forças Armadas & 4,35 & 1,49 & 457 \\
Polícia Militar & 3,67 & 1,54 & 451 \\
Congresso Nacional & 2,52 & 1,30 & 450 \\
Eleições & 2,44 & 1,64 & 459 \\
Partidos políticos & 1,79 & 1,07 & 457 \\
\hline
\end{tabular}

Fonte: Elaboração própria a partir de pesquisa original "Jovens e política".

Tabela D5

Diferenças entre as médias dos itens sobre confiança nas instituições

\begin{tabular}{|lcccl|}
\hline Instituição & $\begin{array}{c}\text { Forças } \\
\text { Armadas }\end{array}$ & Polícia Militar & $\begin{array}{c}\text { Congresso } \\
\text { Nacional }\end{array}$ & Eleições \\
Polícia Militar & $0,67(9,60)^{*}$ & & & \\
Congresso Nacional & $1,83(22,49)^{*}$ & $1,18(14,56)^{*}$ & & \\
Eleições & $1,90(19,16)^{*}$ & $1,24(12,53)^{*}$ & $0,07(0,88)$ & \\
Partidos políticos & $2,56(29,95)^{*}$ & $1,88(22,94)^{*}$ & $0,71(12,64)^{*}$ & $0,64(9,37)^{*}$ \\
\hline
\end{tabular}

Fonte: Elaboração própria a partir de pesquisa original "Jovens e política".

Nota: Diferença entre variável da coluna e da linha, valor t em parênteses. Significância: * $p<0,05$. 
Tabela D6

Correlações entre os itens sobre confiança nas instituições

\begin{tabular}{|lccccc|}
\hline Instituição & $\begin{array}{c}\text { Forças } \\
\text { Armadas }\end{array}$ & $\begin{array}{c}\text { Polícia } \\
\text { Militar }\end{array}$ & $\begin{array}{c}\text { Congresso } \\
\text { Nacional }\end{array}$ & $\begin{array}{c}\text { Partidos } \\
\text { políticos }\end{array}$ & Eleições \\
Forças Armadas & 1 & & & & \\
Polícia Militar & 0,518 & 1 & & & \\
Congresso Nacional & 0,239 & 0,278 & 1 & 1 & \\
Partidos políticos & 0,010 & 0,504 & 0,140 & 0,473 & 1 \\
Eleições & 0,088 & 0,345 & 0,129 & \\
\hline
\end{tabular}

Fonte: Elaboração própria a partir de pesquisa original "Jovens e política".

Figura D2

Distribuição dos escores do fator 1 - "Jovens e política", 2016

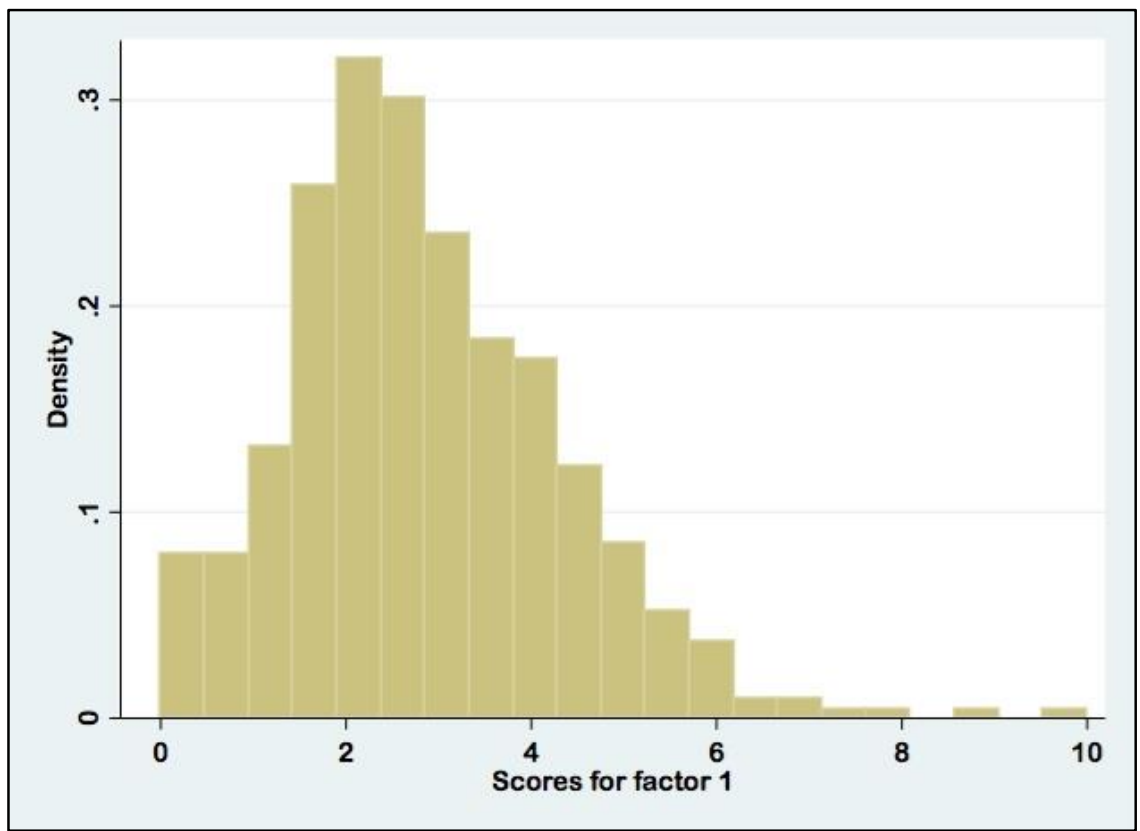

Fonte: Elaboração própria a partir de pesquisa original "Jovens e política". 
Tabelas extras - Barômetro das Américas 2017

Tabela D7

Estatísticas descritivas dos itens sobre confiança nas instituições

\begin{tabular}{|lccc|}
\hline Instituição & Média & Desvio-padrão & Respondentes \\
Forças Armadas & 5,19 & 1,93 & 1.523 \\
Polícia Militar & 4,05 & 1,96 & 1.527 \\
Congresso Nacional & 2,83 & 1,88 & 1.512 \\
Eleições & 2,92 & 1,92 & 1.519 \\
Partidos políticos & 2,09 & 1,54 & 1.525 \\
\hline
\end{tabular}

Fonte: Elaboração própria a partir do Barômetro das Américas (Brasil, 2017).

Tabela D8

Diferenças entre as médias dos itens sobre confiança nas instituições

\begin{tabular}{|lcccc|}
\hline Instituição & $\begin{array}{c}\text { Forças } \\
\text { Armadas }\end{array}$ & Polícia Militar & $\begin{array}{c}\text { Congresso } \\
\text { Nacional }\end{array}$ & Eleições \\
Polícia Militar & $1,12(21,48)^{*}$ & & & \\
Congresso Nacional & $2,35(42,85)^{*}$ & $1,22(21,75)^{*}$ & & \\
Eleições & $2,27(37,94)^{*}$ & $1,13(19,39)^{*}$ & $-0,10(1,89)$ & \\
Partidos políticos & $3,10(55,69)^{*}$ & $1,97(37,85)^{*}$ & $0,74(17,24)^{*}$ & $0,83(18,52)^{*}$ \\
\hline
\end{tabular}

Fonte: Elaboração própria a partir do Barômetro das Américas (Brasil, 2017).

Nota: Diferença entre variável da coluna e linha, valor t em parênteses. Significância: * p<0,05.

Tabela D9

Correlações entre os itens sobre confiança nas instituições

\begin{tabular}{|lccccc|}
\hline Instituição & $\begin{array}{c}\text { Forças } \\
\text { Armadas }\end{array}$ & Polícia Militar & $\begin{array}{c}\text { Congresso } \\
\text { Nacional }\end{array}$ & $\begin{array}{c}\text { Partidos } \\
\text { políticos }\end{array}$ & Eleições \\
Forças Armadas & 1 & & & & \\
Polícia Militar & 0,349 & 1 & & & \\
Congresso Nacional & 0,448 & 0,375 & 1 & 1 & \\
Partidos políticos & 0,196 & 0,534 & 0,373 & 0,504 & 1 \\
Eleições & 0,245 & 0,427 & 0,335 & 0,504 \\
\hline
\end{tabular}

Fonte: Elaboração própria a partir do Barômetro das Américas (Brasil, 2017). 
Figura D3

Distribuição dos escores do fator 1 - Barômetro das Américas, 2017

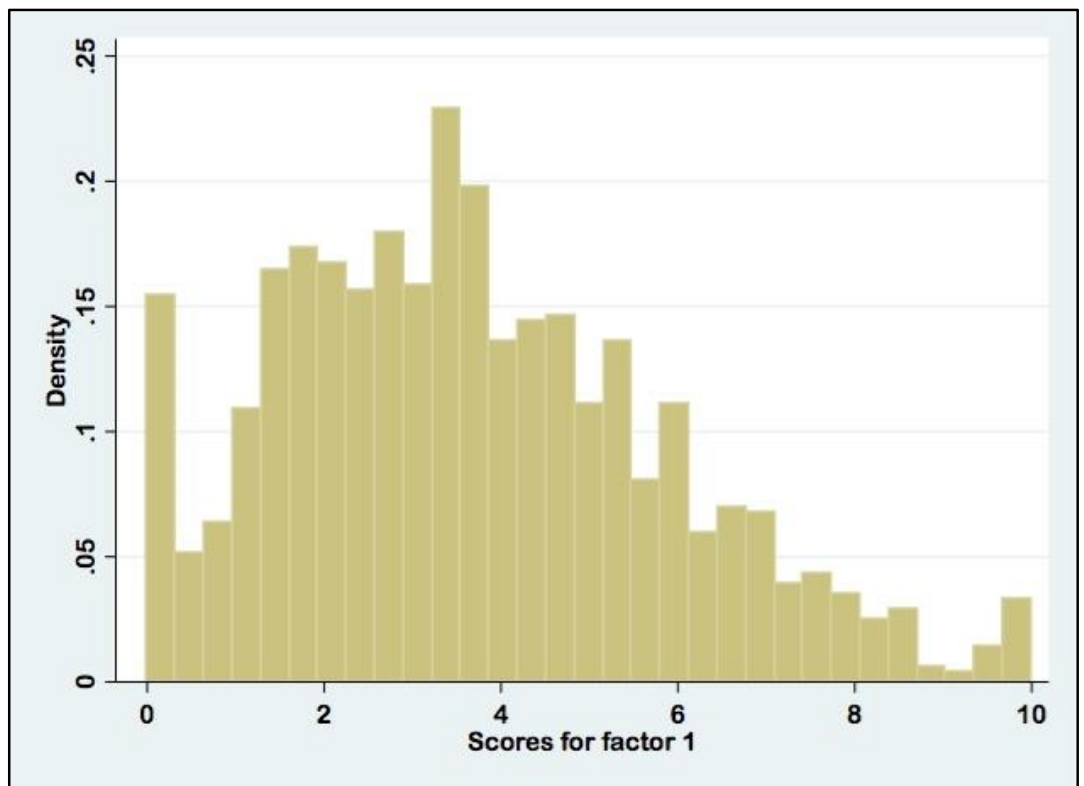

Fonte: Elaboração própria a partir do Barômetro das Américas (Brasil, 2017).

\section{Apêndice E}

E1 - Tabelas de regressão para a Figura 2

\begin{tabular}{|c|c|c|c|c|c|}
\hline & \multirow{2}{*}{$\begin{array}{c}\text { "Jovens e } \\
\text { política" } \\
16-21 \\
\text { anos }\end{array}$} & \multicolumn{2}{|c|}{$\begin{array}{l}\text { Barômetro das } \\
\text { Américas } 2014\end{array}$} & \multicolumn{2}{|c|}{$\begin{array}{l}\text { Barômetro das } \\
\text { Américas } 2017\end{array}$} \\
\hline & & População & $\begin{array}{c}16-24 \\
\text { anos }\end{array}$ & $\begin{array}{c}16-24 \\
\text { anos }\end{array}$ & $\begin{array}{c}16-24 \\
\text { anos }\end{array}$ \\
\hline Fator 1 & $\begin{array}{c}0.213^{* * *} \\
(0.054)\end{array}$ & $\begin{array}{c}0.115 * * * \\
(0.024)\end{array}$ & $\begin{array}{c}0.196 * * * \\
(0.054)\end{array}$ & $\begin{array}{c}0.148 * * * \\
(0.027)\end{array}$ & $\begin{array}{c}0.196 * * * \\
(0.051)\end{array}$ \\
\hline Fator 2 & $\begin{array}{c}0.069 \\
(0.048)\end{array}$ & $\begin{array}{c}-0.065^{* * *} \\
(0.032)\end{array}$ & $\begin{array}{c}-0.078 \\
(0.065)\end{array}$ & $\begin{array}{c}-0.037 \\
(0.035)\end{array}$ & $\begin{array}{c}0.030 \\
(0.063)\end{array}$ \\
\hline \multicolumn{6}{|l|}{ Controles } \\
\hline Sexo & Sim & Sim & Sim & Sim & Sim \\
\hline Idade & Sim & Sim & Sim & Sim & Sim \\
\hline Religião & Sim & Sim & Sim & Sim & Sim \\
\hline Etnia & Sim & Sim & Sim & Sim & Sim \\
\hline Modo & Sim & Não & Não & Não & Não \\
\hline Educação da mãe & Sim & Sim & Sim & Sim & Sim \\
\hline Intercepto & $\begin{array}{c}-0.975 \\
(1.675) \\
\end{array}$ & $\begin{array}{c}4.317 * * * \\
(0.266) \\
\end{array}$ & $\begin{array}{c}3.880 * * * \\
(1.032)\end{array}$ & $\begin{array}{c}3.004 * * * \\
(0.303)\end{array}$ & $\begin{array}{l}1.694^{*} \\
(0.983) \\
\end{array}$ \\
\hline $\begin{array}{l}\text { Número de } \\
\text { respondentes }\end{array}$ & 425 & 1,191 & 278 & 1,038 & 258 \\
\hline $\mathrm{R}^{2}$ (ajustado) & 0.086 & 0.037 & 0.084 & 0.072 & 0.126 \\
\hline
\end{tabular}

Fonte: Elaboração própria a partir dados do Barômetro das Américas (Brasil, 2014, 2017) e da pesquisa "Jovens e política", 2016.

Nota: Coeficientes não padronizados e respectivos erros-padrão entre parênteses.

Significância: *** $\mathrm{p}<0,01, * * \mathrm{p}<0,05, * \mathrm{p}<0,10$. 


\section{Apêndice F}

O número de casos com missing value para a variável ED2 (educação da mãe) é alto na pesquisa do Barômetro das Américas de 2017 (Tabela B1 no Apêndice B), por isso, a variável foi retirada dos modelos apresentados nas Tabelas 2 e 3 do artigo. No entanto, apresentam-se os resultados dos mesmos modelos incluindo essa variável aqui.

\section{Tabelas de regressão F1 e F2 com educação da mãe}

Tabela F1

Correlatos da confiança nas instituições, 2016

\begin{tabular}{|l|c|c|}
\hline & Coeficiente & (Erro-padrão) \\
\hline Participação em organização comunitária & 0.09 & $(0.14)$ \\
\hline Participação em partido político & -0.08 & $(0.14)$ \\
\hline Participação em audiência pública & $0.27^{* *}$ & $(0.07)$ \\
\hline Consumo de notícias via rádio & $0.26^{*}$ & $(0.14)$ \\
\hline Consumo de notícias via internet & $-0.43^{*}$ & $(0.24)$ \\
\hline Consumo de notícias via televisão & 0.15 & $(0.22)$ \\
\hline Consumo de notícias via redes sociais & -0.05 & $(0.18)$ \\
\hline Índice de eficácia interna & $0.03 * *$ & $(0.01)$ \\
\hline Sexo feminino & $-0.24 * *$ & $(0.11)$ \\
\hline Escolaridade da mãe & -0.01 & $(0.12)$ \\
\hline Questionário online (Papel=0) & 0.16 & $(0.13)$ \\
\hline Católico & \multicolumn{2}{|c|}{ Referência } \\
\hline Protestante tradicional / Evangélico & -0.13 & $(0.24)$ \\
\hline Evangélica pentecostal & 0.27 & $(0.20)$ \\
\hline Nenhuma religião & -0.09 & $(0.25)$ \\
\hline Agnóstico / Ateu & -0.42 & $(0.26)$ \\
\hline Outro & -0.26 & $(0.17)$ \\
\hline Intercepto & 3.76 & $(0.74)$ \\
\hline Número de respondentes & \multicolumn{2}{|c|}{0.02} \\
\hline$R^{2}$ (ajustado) & \multicolumn{2}{|c|}{} \\
\hline Fonte: Elaboração própria a partir de pesquisa original \\
Nota: Coeficientes não padronizados (erros-padrão entre parênteses). \\
Significância: * p<0.05, ** p<0.10.
\end{tabular}


Tabela F2

Correlatos de confiança nas instituições, 2014 e 2017

\begin{tabular}{|c|c|c|c|c|c|c|c|c|}
\hline \multirow{3}{*}{\begin{tabular}{|l|} 
\\
\\
$\begin{array}{l}\text { Participação em org. } \\
\text { comunitária }\end{array}$ \\
\end{tabular}} & \multicolumn{4}{|c|}{ Barômetro das Américas 2014} & \multicolumn{4}{|c|}{ Barômetro das Américas 2017} \\
\hline & \multicolumn{2}{|c|}{ População } & \multicolumn{2}{|c|}{$16-24$ anos } & \multicolumn{2}{|c|}{ População } & \multicolumn{2}{|c|}{ 16-24 anos } \\
\hline & $\begin{array}{c}0.134 \\
(0.116) \\
\end{array}$ & $\begin{array}{c}0.076 \\
(0.076) \\
\end{array}$ & $\begin{array}{l}0.496 * * \\
(0.243) \\
\end{array}$ & $\begin{array}{c}0.263 \\
(0.217) \\
\end{array}$ & $\begin{array}{c}0.136 \\
(0.114) \\
\end{array}$ & $\begin{array}{c}0.160 \\
(0.112) \\
\end{array}$ & $\begin{array}{c}0.172 \\
(0.177)\end{array}$ & $\begin{array}{c}0.246 \\
(0.177) \\
\end{array}$ \\
\hline $\begin{array}{l}\text { Participação em partido } \\
\text { político }\end{array}$ & $\begin{array}{c}0.560^{* * *} \\
(0.153)\end{array}$ & $\begin{array}{l}0.313^{* *} \\
(0.129)\end{array}$ & $\begin{array}{l}0.389^{*} \\
(0.227)\end{array}$ & $\begin{array}{l}0.351^{*} \\
(0.212) \\
\end{array}$ & $\begin{array}{c}0.058 \\
(0.105)\end{array}$ & $\begin{array}{c}0.053 \\
(0.092)\end{array}$ & $\begin{array}{l}-0.009 \\
(0.180)\end{array}$ & $\begin{array}{c}0.009 \\
(0.157) \\
\end{array}$ \\
\hline Consumo de notícias & $\begin{array}{l}-0.080 \\
(0.077)\end{array}$ & $\begin{array}{l}-0.064 \\
(0.063)\end{array}$ & $\begin{array}{l}-0.082 \\
(0.120)\end{array}$ & $\begin{array}{l}-0.053 \\
(0.110)\end{array}$ & $\begin{array}{l}-0.133^{*} \\
(0.072)\end{array}$ & $\begin{array}{c}-0.129^{*} \\
(0.069)\end{array}$ & $\begin{array}{l}-0.188^{*} \\
(0.112)\end{array}$ & $\begin{array}{l}-0.168 \\
(0.112)\end{array}$ \\
\hline Uso de internet & $\begin{array}{c}-0.178^{* * *} \\
(0.052)\end{array}$ & $\begin{array}{l}-0.027 \\
(0.039)\end{array}$ & $\begin{array}{c}-0.265^{* *} \\
(0.104)\end{array}$ & $\begin{array}{l}-0.084 \\
(0.075)\end{array}$ & $\begin{array}{l}-0.053 \\
(0.056)\end{array}$ & $\begin{array}{l}-0.050 \\
(0.053)\end{array}$ & $\begin{array}{l}-0.129 \\
(0.153)\end{array}$ & $\begin{array}{l}-0.125 \\
(0.156)\end{array}$ \\
\hline Eficácia interna & $\begin{array}{c}0.165^{* * *} \\
(0.040) \\
\end{array}$ & $\begin{array}{c}0.088^{* * * *} \\
(0.030)\end{array}$ & $\begin{array}{c}0.240 * * * \\
(0.076) \\
\end{array}$ & $\begin{array}{c}0.095 \\
(0.064) \\
\end{array}$ & $\begin{array}{c}0.147 * * * \\
(0.038) \\
\end{array}$ & $\begin{array}{c}0.115^{* * *} \\
(0.036) \\
\end{array}$ & $\begin{array}{l}-0.009 \\
(0.102) \\
\end{array}$ & $\begin{array}{c}0.037 \\
(0.091) \\
\end{array}$ \\
\hline Sexo feminino & $\begin{array}{c}0.157 \\
(0.126)\end{array}$ & $\begin{array}{c}0.138 \\
(0.100)\end{array}$ & $\begin{array}{c}0.115 \\
(0.221)\end{array}$ & $\begin{array}{c}0.144 \\
(0.177)\end{array}$ & $\begin{array}{c}-0.306^{* *} \\
(0.144)\end{array}$ & $\begin{array}{l}-0.002 \\
(0.127)\end{array}$ & $\begin{array}{l}-0.222 \\
(0.291)\end{array}$ & $\begin{array}{c}0.203 \\
(0.270)\end{array}$ \\
\hline Idade (em anos) & $\begin{array}{l}-0.008 \\
(0.006)\end{array}$ & $\begin{array}{c}0.003 \\
(0.004) \\
\end{array}$ & $\begin{array}{c}-0.129 * * * \\
(0.048) \\
\end{array}$ & $\begin{array}{l}-0.061 \\
(0.037) \\
\end{array}$ & $\begin{array}{l}-0.009 \\
(0.006)\end{array}$ & $\begin{array}{c}-0.013^{* *} \\
(0.005) \\
\end{array}$ & $\begin{array}{c}-0.177 * * * \\
(0.056)\end{array}$ & $\begin{array}{c}-0.154 * * * \\
(0.052) \\
\end{array}$ \\
\hline Ensino fundamental & $\begin{array}{c}-1.088 * * \\
(0.457)\end{array}$ & $\begin{array}{l}-0.272 \\
(0.300)\end{array}$ & . & & $\begin{array}{l}-0.080 \\
(0.579)\end{array}$ & $\begin{array}{l}-0.342 \\
(0.567)\end{array}$ & & - \\
\hline Ensino médio & $\begin{array}{c}-1.429 * * * \\
(0.469)\end{array}$ & $\begin{array}{l}-0.336 \\
(0.308)\end{array}$ & $\begin{array}{l}-0.265 \\
(0.513)\end{array}$ & $\begin{array}{c}0.058 \\
(0.425)\end{array}$ & $\begin{array}{l}-0.315 \\
(0.600)\end{array}$ & $\begin{array}{l}-0.532 \\
(0.581)\end{array}$ & $\begin{array}{l}-0.156 \\
(0.413)\end{array}$ & $\begin{array}{l}-0.057 \\
(0.373)\end{array}$ \\
\hline Ensino superior & $\begin{array}{c}-1.753 * * * \\
(0.492) \\
\end{array}$ & $\begin{array}{l}-0.515 \\
(0.355) \\
\end{array}$ & $\begin{array}{l}-0.323 \\
(0.641) \\
\end{array}$ & $\begin{array}{l}-0.143 \\
(0.600) \\
\end{array}$ & $\begin{array}{l}-0.613 \\
(0.619) \\
\end{array}$ & $\begin{array}{l}-0.783 \\
(0.595) \\
\end{array}$ & $\begin{array}{l}-0.058 \\
(0.691) \\
\end{array}$ & $\begin{array}{c}0.195 \\
(0.663) \\
\end{array}$ \\
\hline Educação da mãe & $\begin{array}{c}0.060 \\
(0.046)\end{array}$ & $\begin{array}{c}0.025 \\
(0.028)\end{array}$ & $\begin{array}{l}-0.027 \\
(0.062)\end{array}$ & $\begin{array}{l}-0.029 \\
(0.048)\end{array}$ & $\begin{array}{l}-0.006 \\
(0.035)\end{array}$ & $\begin{array}{l}-0.025 \\
(0.035)\end{array}$ & $\begin{array}{c}0.018 \\
(0.086)\end{array}$ & $\begin{array}{l}-0.035 \\
(0.076)\end{array}$ \\
\hline Católico & \multicolumn{8}{|c|}{ Referência } \\
\hline $\begin{array}{l}\text { Protestante trad. / } \\
\text { Evangélico }\end{array}$ & $\begin{array}{l}-0.063 \\
(0.212)\end{array}$ & $\begin{array}{c}0.099 \\
(0.170)\end{array}$ & $\begin{array}{l}-0.562 \\
(0.372)\end{array}$ & $\begin{array}{l}-0.435^{*} \\
(0.259)\end{array}$ & $\begin{array}{l}-0.263 \\
(0.195)\end{array}$ & $\begin{array}{l}-0.230 \\
(0.175)\end{array}$ & $\begin{array}{c}0.077 \\
(0.441)\end{array}$ & $\begin{array}{c}0.115 \\
(0.394)\end{array}$ \\
\hline Nenhuma religião & $\begin{array}{l}-0.425^{*} \\
(0.228) \\
\end{array}$ & $\begin{array}{c}0.028 \\
(0.182) \\
\end{array}$ & $\begin{array}{c}-0.954 * * \\
(0.468) \\
\end{array}$ & $\begin{array}{l}-0.410 \\
(0.316) \\
\end{array}$ & $\begin{array}{c}-0.556^{* *} \\
(0.228) \\
\end{array}$ & $\begin{array}{c}-0.508^{* * *} \\
(0.188) \\
\end{array}$ & $\begin{array}{l}-0.496 \\
(0.491) \\
\end{array}$ & $\begin{array}{l}-0.118 \\
(0.460) \\
\end{array}$ \\
\hline Evangélica pentecostal & $\begin{array}{l}-0.083 \\
(0.164) \\
\end{array}$ & $\begin{array}{c}0.107 \\
(0.122) \\
\end{array}$ & $\begin{array}{l}-0.527^{*} \\
(0.287)\end{array}$ & $\begin{array}{l}-0.378^{*} \\
(0.223) \\
\end{array}$ & $\begin{array}{c}0.231 \\
(0.170) \\
\end{array}$ & $\begin{array}{c}0.132 \\
(0.166) \\
\end{array}$ & $\begin{array}{c}0.266 \\
(0.396) \\
\end{array}$ & $\begin{array}{c}0.247 \\
(0.364) \\
\end{array}$ \\
\hline Agnóstico / Ateu & $\begin{array}{c}-0.797^{* *} \\
(0.398)\end{array}$ & $\begin{array}{c}0.125 \\
(0.291)\end{array}$ & $\begin{array}{c}-1.364 * * * \\
(0.322)\end{array}$ & $\begin{array}{l}-0.053 \\
(0.441)\end{array}$ & $\begin{array}{c}-1.488^{* * *} \\
(0.446)\end{array}$ & $\begin{array}{c}-0.987^{* *} \\
(0.451)\end{array}$ & $\begin{array}{l}-0.773 \\
(1.248)\end{array}$ & $\begin{array}{l}-0.313 \\
(1.083)\end{array}$ \\
\hline Outro & $\begin{array}{c}-0.872 * * * \\
(0.292)\end{array}$ & $\begin{array}{l}-0.436 * \\
(0.259) \\
\end{array}$ & $\begin{array}{c}-1.572 * * \\
(0.730) \\
\end{array}$ & $\begin{array}{l}-0.659 \\
(0.402) \\
\end{array}$ & $\begin{array}{c}-0.633^{* * * *} \\
(0.238)\end{array}$ & $\begin{array}{c}-0.504 * * \\
(0.217) \\
\end{array}$ & $\begin{array}{l}-0.905^{*} \\
(0.502) \\
\end{array}$ & $\begin{array}{l}-0.674 \\
(0.422) \\
\end{array}$ \\
\hline $\begin{array}{l}\text { Percepção da economia } \\
\text { pessoal }\end{array}$ & & $\begin{array}{l}-0.122^{*} \\
(0.071)\end{array}$ & & $\begin{array}{l}-0.076 \\
(0.131)\end{array}$ & & $\begin{array}{l}-0.128 \\
(0.080)\end{array}$ & & $\begin{array}{l}-0.203 \\
(0.171)\end{array}$ \\
\hline Confiança interpessoal & & $\begin{array}{l}0.166 * * \\
(0.067) \\
\end{array}$ & & $\begin{array}{c}0.006 \\
(0.109) \\
\end{array}$ & & $\begin{array}{c}0.342 * * * \\
(0.068) \\
\end{array}$ & & $\begin{array}{l}0.270^{*} \\
(0.162) \\
\end{array}$ \\
\hline $\begin{array}{l}\text { Avaliação do governo } \\
\text { ao combate à corrupção }\end{array}$ & & $\begin{array}{c}0.226 * * * \\
(0.045)\end{array}$ & & $\begin{array}{l}0.177^{* *} \\
(0.074)\end{array}$ & & . & & . \\
\hline $\begin{array}{l}\text { Avaliação do governo } \\
\text { sobre segurança }\end{array}$ & & $\begin{array}{c}0.473^{* * *} \\
(0.056)\end{array}$ & & $\begin{array}{c}0.430 * * * \\
(0.083)\end{array}$ & & . & & . \\
\hline $\begin{array}{l}\text { Avaliação do governo } \\
\text { sobre economia }\end{array}$ & & $\begin{array}{c}0.181^{* * *} \\
(0.042)\end{array}$ & & $\begin{array}{c}0.231 * * * \\
(0.088)\end{array}$ & & . & & . \\
\hline $\begin{array}{l}\text { Avaliação da(o) } \\
\text { presidente }\end{array}$ & & . & & . & & $\begin{array}{c}0.650 * * * \\
(0.061)\end{array}$ & & $\begin{array}{c}0.747 * * * \\
(0.124)\end{array}$ \\
\hline Intercepto & $\begin{array}{c}4.596 * * * \\
(0.768) \\
\end{array}$ & $\begin{array}{c}0.372 \\
(0.616) \\
\end{array}$ & $\begin{array}{c}6.476 * * * \\
(1.437) \\
\end{array}$ & $\begin{array}{l}2.151 * * \\
(1.072) \\
\end{array}$ & $\begin{array}{c}4.750 * * * \\
(0.724) \\
\end{array}$ & $\begin{array}{c}2.822 * * * \\
(0.735) \\
\end{array}$ & $\begin{array}{c}8.934 * * * \\
(1.533) \\
\end{array}$ & $\begin{array}{c}5.683 * * * \\
(1.619) \\
\end{array}$ \\
\hline $\begin{array}{l}\text { Número de } \\
\text { respondentes }\end{array}$ & 1,209 & 1,174 & 284 & 280 & 1,043 & 1,028 & 259 & 258 \\
\hline $\mathrm{R}^{2}$ (ajustado) & 0.087 & 0.446 & 0.165 & 0.474 & 0.062 & 0.199 & 0.091 & 0.22 \\
\hline
\end{tabular}

Fonte: Elaboração própria a partir de dados do Barômetro das Américas, Brasil, 2014 e 2017.

Nota: Coeficientes não padronizados com os respectivos erros-padrão entre parênteses. Significância: $* * * \mathrm{p}<0.01, * * \mathrm{p}<0.05, * \mathrm{p}<0.10$. 


\begin{abstract}
Trust in political institutions: differences and interdependency in the opinions of the Brazilian youth and population This article contributes to the study of trust in institutions in Brazil by analyzing data from the 2014 and 2017 AmericasBarometer surveys, as well as from an original survey of 487 young adults conducted in 2016 . The objectives of the article are: 1 ) to identify variation in the level of confidence in different institutions and across both the general population and young adults specifically; 2) to map the extent to which opinions of the different institutions relate to one another; 3 ) to assess the relationship between experiences of political participation, media consumption, and trust in institutions. The results indicate that political institutions such as parties and elections are viewed negatively, especially when compared to the Armed Forces. Factor analysis indicates that opinions about institutions are organized in two dimensions, one that captures the propensity to have more trust in institutions and another that discriminates favorable views of the military institutions. Regression analysis indicates that individuals who attended political meetings and used the Internet less often have a higher level of trust in institutions.
\end{abstract}

Keywords: trust in institutions; public opinion; social cognitive theory; youth

\title{
Resumen
}

Confianza en las instituciones políticas: diferencias e interdependencia en las opiniones de jóvenes y población brasileña

Este artículo contribuye al estudio sobre confianza en las instituciones en Brasil al analizar los datos del Barómetro de las Américas de 2014, de 2017 y de una encuesta original con 487 jóvenes en 2016. Los objetivos son: 1) identificar variación en los niveles de confianza en diferentes instituciones y entre la población general y los jóvenes, 2) mapear cómo las opiniones dentro de las diferentes instituciones se relacionan entre sí, y 3) evaluar la relación entre experiencias de participación política, consumo de medios, y confianza en las instituciones. Los resultados indican que las instituciones políticas como partidos y elecciones son vistas de forma negativa, principalmente si son comparadas con las Fuerzas Armadas. Los análisis factoriales indican que las opiniones sobre instituciones se organizan en dos dimensiones, una que captura la propensión a tener más confianza en las instituciones y otra que discrimina opiniones favorables a las instituciones militares. Los análisis de regresión indican que los individuos que atendieron a reuniones políticas y utilizaron menos Internet tienen un nivel de confianza más alto en las instituciones. Palabras clave: confianza en las instituciones; opinión pública; teoría social cognitiva; jóvenes

\section{Résumé}

Confiance dans les institutions politiques: les différences et l'interdépendance dans les opinions des jeunes et de la population brésilienne

Cet article contribue à l'étude sur la confiance dans les institutions brésiliennes lors de l'analyse des sondages du Baromètre des Amériques de 2014, de 2017 et d'une enquête originale auprès de 487 jeunes en 2016. Les objectifs sont 1) d'identifier la variation de niveaux de confiance dans différentes institutions et parmi la population générale et les jeunes, 2) d'indiquer comment les opinions dans les différentes institutions sont liées les unes aux autres, et 3) d'analyser la relation entre les expériences de participation politique, la consommation des médias et la confiance dans les institutions. Les résultats montrent que les institutions politiques telles que les partis et les élections sont perçues négativement, en particulier si on les compare aux forces armées. Des analyses factorielles indiquent que les opinions sur les institutions sont réparties en deux dimensions: I'une reflète la propension à avoir plus confiance dans les institutions et l'autre discrimine les opinions favorables aux institutions militaires. Enfin, les analyses de régression indiquent que les personnes qui ont assisté à des réunions politiques et utilisent moins souvent Internet ont un niveau de confiance plus élevé dans les institutions.

Mots-clés: confiance dans les institutions; opinion publique; théorie sociale cognitive; jeunes

Artigo submetido à publicação em 19 de outubro de 2017. Versão final aprovada em 28 de junho de 2018.

Opinião Pública adota a licença Creative Commons CC-BY. 